\title{
Effects of defoliation modalities on plant growth, leaf traits, and carbohydrate allocation in Amorpha fruticosa L. and Robinia pseudoacacia L. seedlings
}

\author{
Ning Wang ${ }^{1,2} \cdot$ Mingming Zhao ${ }^{1,2} \cdot$ Qiang $\mathrm{Li}^{1,2} \cdot$ Xiao Liu $^{1,2} \cdot$ Huijia Song ${ }^{1,2} \cdot$ Xiqiang Peng ${ }^{1,2} \cdot$ Hui Wang $^{1,2} \cdot$ \\ Ning Yang ${ }^{3} \cdot$ Peixian Fan $^{3} \cdot$ Renqing Wang ${ }^{1,2} \cdot$ Ning Du $^{1,2}$
}

Received: 20 January 2020 / Accepted: 13 April 2020 / Published online: 26 May 2020

(C) INRAE and Springer-Verlag France SAS, part of Springer Nature 2020

\begin{abstract}
- Key message Defoliation modality significantly affected leaf traits and carbon allocation especially in the early recovery period of two Leguminosae woody species. Robinia pseudoacacia L. recovered more quickly following defoliation than Amorpha fruticosa $\mathrm{L}$.

- Context Defoliation resulting from anthropogenic disturbance, insects, and grazing animals affects plant growth and vegetation dynamics. Robinia pseudoacacia L. and Amorpha fruticosa L. with different susceptibility to biotic attack are commonly used for vegetation restoration in North China. However, plant responses to defoliation were not fully understood in the two Leguminosae woody species.

- Aims We selected R. pseudoacacia and A. fruticosa to determine the effects of defoliation on individual plant growth, leaf traits, and carbohydrate allocation and compared the two species in terms of recovery strategies following defoliation for vegetation restoration.

- Methods In a greenhouse experiment, A. fruticosa and R. pseudoacacia seedlings were subjected to three defoliation treatments: defoliation of the top down (TD) or bottom up (BU) $50 \%$ of the crown, and a control without defoliation (CK). The physiological and growth traits of seedlings were determined at 1, 3, 14, 30, and 60 days following defoliation.
\end{abstract}

Handling Editor: Erwin Dreyer

Contributions of the co-authors All authors make a contribution to this work. Ning Wang and Mingming Zhao participated in the experiment. Qiang Li, Xiao Liu, Huijia Song, and Xiqang Peng participated in the data analysis. Hui Wang, Ning Yang, Peixian Fan, Renqing Wang, and Ning Du participated in the paper writing and revision.

Renqing Wang

rqwang@sdu.edu.cn

Ning Du

duning_sdu@126.com

Ning Wang

1103779969@qq.com

Mingming Zhao

17860721280@163.com

Qiang Li

liqiang_sdu@163.com

Xiao Liu

flippedlx@foxmail.com

Huijia Song

huijiasong@foxmail.com
Xiqiang Peng

1027344024@qq.com

Hui Wang

wanghui1227@sdu.edu.cn

Ning Yang

13153288996@163.com

Peixian Fan

qdlinye@163.com

1 Institute of Ecology and Biodiversity, School of Life Sciences, Shandong University, 72 Binhai Road, Qingdao 266237, China

2 Shandong Provincial Engineering and Technology Research Center for Vegetation Ecology, Shandong University, 72 Binhai Road, Qingdao 266237, China

3 Qingdao Forestry Station, 106 Yan'an'yi Road, Qingdao 266003, China 
- Results Plant growth in both species recovered after 2 months whatever defoliation modalities. Carbon allocation in both species was greatly affected by defoliation modalities during the early recovery period but had been fully recovered after 60 days of treatment. In the end of the experiment, defoliation modalities still had obvious impacts on leaf characteristics, especially in chlorophyll concentration and specific leaf area. $R$. pseudoacacia exhibited more evident compensatory mechanisms than A. fruticosa following defoliation.

- Conclusion Defoliation modality treatments significantly affect most leaf traits and carbon allocation, especially in the early recovery period of both species. Considering the faster recovery ability of $R$. pseudoacacia than A. fruticosa after defoliation, $R$. pseudoacacia seedlings may be more suitable for vegetation restoration in North China.

Keywords Leaf damage $\cdot$ Leaf morphology $\cdot$ Photosynthetic rate $\cdot$ Recovery stage

\section{Introduction}

Plants often suffer from leaf damage due to anthropogenic disturbance, insects, and grazing animals, especially in the context of increasing anthropogenic activities and changing climate conditions (Eyles et al. 2013a, b). As the climate changes, warmer temperatures and drier conditions may become more widespread and occur more frequently. These changes would increase the fitness and abundance of some forest pests (Dale and Frank 2017; Root et al. 2003), affecting plant growth and vegetation dynamics (Kuosmanen et al. 2018; Leather et al. 2010; Yang et al. 2005). Studying the influence of biological disturbance on young trees and the response of individual plants may provide a theoretical basis for selecting and managing species for vegetation restoration. Defoliation experiments are commonly used to simulate biological disturbance on plant species (Wiley et al. 2017; Wyka et al. 2017). Leaf removal decreases leaf photosynthetic area and affects root vigor, plant nutrient concentrations, secondary metabolite, and non-structural carbohydrate (NSC) content (Eyles et al. 2013a, b; Karolewski et al. 2010; Wiley et al. 2013). Thus, the recovery process and the allocation and partitioning of carbohydrates in individual plants following defoliation are important research topics in the study of plant ecology for developing improved management strategies (Barry et al. 2012; Jacquet et al. 2014; Quentin et al. 2010; Wiley et al. 2017).

Leaves are the main organ used for production of organic matter and are the main source of carbohydrates for a plant (Liu et al. 2017). Stems and roots are long-term storage organs and represent important carbon sinks (Lourens et al. 2010). The accumulation of carbohydrates in the leaves depends on the balance between carbon sources and sinks and the transport of carbohydrates in the phloem (Asao and Ryan 2015; Galiano et al. 2011). Sources provide assimilates through phloem transport to sinks that compete with each other (Dewar 1993). Carbohydrates are the main product of plant photosynthesis and are divided into structural carbohydrates and NSCs (Asao and Ryan 2015; Piper et al. 2017). NSCs are commonly used to assess the balance between carbon sources and sinks in plants (Bansal and Germino 2009). Carbohydrate concentration and its transport are indicators of the ecological strategies of trees, and they are important parameters in the development of tree growth and forest carbon cycle models (Chuste et al. 2019; Hinman and Fridley 2018; Richardson et al. 2013).

Generally, species, even in the same genus, respond differently after defoliation, and the time and extent of recovery vary. The responses of Eucalyptus globulus and Eucalyptus nitens to defoliation were similar, and growth (height and stem diameter) was found to have significantly reduced after defoliation (Barry and Pinkard 2013). However, the responses of white oak (Quercus alba) and black oak (Quercus velutina) to defoliation were different. White oak significantly changed in above-ground biomass, while black oak had a more pronounced chemical change in foliar chemistry after defoliation (Rieske and Dillaway 2008). After full defoliation, Quercus velutina seedlings had lower starch levels than those in the control in the short term but could recover to control levels in the longer term (Wiley et al. 2013). In another evergreen oak species, Quercus ilex, carbohydrate reserves were also found to decrease in the short term after defoliation (Schmid et al. 2017). However, in the deciduous Quercus petraea, NSC tissue concentrations were not found to decrease either in the short term or in the longer time after defoliation (Schmid et al. 2017). Deciduous larches and evergreen pines were also found to respond differently to defoliation. Defoliation reduced Larix decidua height growth but had no effect on radial growth, while Pinus resinosa stem radial growth decreased immediately, but height did not decrease until the following year (Krause and Raffa 1996). Consequently, these findings suggest that after leaf area is severely decreased, the recovery ability is species specific.

The extent and timing of recovery of individual plants after leaf removal may also be related to leaf defoliation modalities. Leaf position within canopy influences photosynthesis (Nautiyal et al. 1999). Defoliation pattern had no effect on the incident light reaching the upper or mid-crown. Thus, defoliation of the upper crown is likely to increase the penetration of light throughout the crown (Quentin et al. 2011), 
which may increase the productivity of the lower crown. In addition, defoliation of the upper crown would decrease branch senescence in the lower crown and increase the rate of leaf area production in the mid-crown as well as mean specific leaf area (SLA) (Quentin et al. 2011). The upper leaves are functionally different from the lower leaves, which have higher photosynthetic activities than the upper leaves during the vigorous growth period (Wilson and Cooper 1969). Leaves will transform from carbon sinks to carbon sources with growth development. However, the effect of lower crown defoliation on plant growth and physiological traits has rarely been reported. Therefore, irrespective of leaf senesce, the lower leaves are regarded as a mature carbon source at the seedling stage, while the upper leaves are regarded as a partially underdeveloped carbon pool. The defoliation of the lower leaves should have a greater impact on carbohydrate production; therefore, we suspect that the recovery pattern will be different based on leaf defoliation modalities. The photosynthetic ability of the remaining leaves will increase (Qiu et al. 2016) and plants rapidly produce new leaves (Korpita and Orians 2014) after defoliation. However, how to select the most economical strategy for rapid recovery under different defoliation modalities remains unclear.

In the present study, two leguminous woody species, Robinia pseudoacacia L. and Amorpha fruticosa L., were selected to study the effects of different defoliation modalities on individual plant growth, carbohydrate allocation, and leaf traits. R. pseudoacacia is the dominant species in the tree layer of forests in the warm temperate zone, while A. fruticosa is normally found in the shrub layer as an important companion species (Wang and Zhou 2000). Both species are commonly used for vegetation restoration in warm temperate regions, owing to their rapid growth rates (Dehaan et al. 2006; Guo et al. 2018). Although R. pseudoacacia is listed as an invasive species, it has not caused much harm and is widely used in the afforestation and vegetation restoration in warm temperate zones of China for several years (Cierjacks et al. 2013; Petrović et al. 2016; Weber et al. 2008). R. pseudoacacia has been planted since the 1980s in China for the purpose of vegetation restoration with approximately 8000 ha planted (Zhang and Xing 2009). However, the numbers of insect pests associated with $R$. pseudoacacia have greatly increased, such as Cyclopelta siccifolia and Bagrada cruciferarum (Sharma et al. 2008). These pests feed on new shoots and leaves of R. pseudoacacia. For R. pseudoacacia, Phyllactinia moricola is a fungus mainly harmful to leaves, mainly occurring on the back of mature leaves but also in the early stage of seedlings; the symptom starts from the lower leaves. However, A. fruticosa is not susceptible to diseases and insect pests. To our knowledge, no previous studies have reported the effects of defoliation modalities on $R$. pseudoacacia and A. fruticosa. Therefore, in the present study, three different defoliation treatments were set up in a greenhouse experiment to measure plant growth, leaf traits, and carbohydrate allocation. We hypothesized that (i) defoliation reduces plant growth in terms of height and biomass at the end of the experiment, (ii) physiological compensatory mechanisms differ between the defoliation of top and bottom leaves, and (iii) $R$. pseudoacacia and A. fruticosa have different recovery strategies after defoliation.

\section{Material and methods}

\subsection{Site}

The study was conducted at Fanggan Research Station of Shandong University in Jinan, Shandong province, China $\left(36^{\circ} 26^{\prime} \mathrm{N}, 117^{\circ} 27^{\prime} \mathrm{E}\right)$, which is in the warm temperate zone with mean annual precipitation of $700 \pm 100 \mathrm{~mm}$ and an average temperature of $13 \pm 1{ }^{\circ} \mathrm{C}$. Seedlings were irrigated every second day, each time to saturation. The experiment was carried out in a greenhouse with a steel pipe frame covered by a plastic film. The greenhouse had a light transmittance of $66 \%$. During the growth period, the microclimate in the greenhouse was monitored with HOBO data loggers (U12-012, Onset, Bourne, MA, USA): mean air temperature of $29.6^{\circ} \mathrm{C}$ $\left(18.7-36.7^{\circ} \mathrm{C}\right)$ in the daytime and $20.8^{\circ} \mathrm{C}\left(10.2-27.5^{\circ} \mathrm{C}\right)$ at night, mean relative humidity of $59.3 \%(28.2-97.8 \%)$ in the daytime and $93.6 \%(56.3-100 \%)$ at night.

\subsection{Plant materials}

Seeds of R. pseudoacacia and A. fruticosa were purchased from Qiluyuanyi Seed Company (Linyi, China) and were collected from their own garden in the early winter of 2016. The seeds were stored at $0-4{ }^{\circ} \mathrm{C}$ through the winter. In late April of 2017, after soaking in distilled water for $24 \mathrm{~h}$, the seeds were allowed to germinate in a growth chamber. When most radicles reached $2 \mathrm{~cm}$, healthy and uniform germinants were sown in plastic pots $(25 \times 21 \mathrm{~cm}$, height $\times$ diameter; one plant per pot) with 7-kg mixed sandy loam and humus soil and allowed to grow for 3 months.

\subsection{Experimental design}

For each species, 3-month-old vigorous seedlings of similar size were selected and randomly assigned to treatments. The initial plant height of $A$. fruticosa was about $0.34 \pm 0.01 \mathrm{~m}$, and the initial plant height of $R$. pseudoacacia was about 0.75 $\pm 0.01 \mathrm{~m}$. The three defoliation treatments were as follows: defoliation of top down $50 \%$ of the crown height (TD), defoliation of the bottom up $50 \%$ of the crown height (BU); and a control group without leaf removal (CK). The treatments were conducted from July 6 to September 4 . There were 20 replicates in each treatment for each species. During the 
experiment, seedlings were harvested at days 1 (July 7), 3 (July 9), 14 (July 20), 30 (August 5), and 60 (September 4). Four individuals of each species and treatment were randomly selected to measure in each sampling.

\subsection{Growth measurements}

Seedling height $(\mathrm{H})$ and total biomass were recorded at each harvest. Four seedlings in each treatment were harvested at around noon (12:00-3:00 pm) and separated into roots, stems, and leaves. Then, the samples were oven-dried (30 min at $105^{\circ} \mathrm{C}$, followed by $72 \mathrm{~h}$ at $75^{\circ} \mathrm{C}$ ) and weighed. Total biomass (TB) was calculated as follows:

$\mathrm{TB}=\mathrm{RB}+\mathrm{SB}+\mathrm{LB}$

where TB is the total biomass, RB is the root biomass, $\mathrm{SB}$ is the stem biomass, and LB is the leaf biomass.

\subsection{Leaf morphological and physiological traits}

After 60 days of treatment, leaf morphological and physiological traits were measured at the beginning of September. For each species, 50 fully expanded and healthy reflushing leaves from the upper part of each seedling were scanned, and images were analyzed with the WinFOLIA Pro 2009a software (Regent Instruments, Inc., Quebec, QC, Canada) to determine leaf area. Leaf thickness was measured with an electronic digital micrometer and was averaged from 20 fresh leaves per seedling. After scanning, these leaves were oven-dried for $72 \mathrm{~h}$ at $75^{\circ} \mathrm{C}$ and weighed. SLA was calculated as leaf area/leaf dry mass.

Three fully expanded and healthy leaves from the upper shoots (one leaf per seedling) in each treatment in both species were sampled to determine leaf chlorophyll concentration. After extraction by $95 \%$ ethanol $(v / v)$, the concentration of leaf chlorophyll $\mathrm{a}$ and $\mathrm{b}$ and total chlorophyll concentration were determined using the spectrophotometric method according to Lichtenthaler and Wellburn (1983). Net photosynthetic rate (A) of seedlings was measured before each harvest at days 1 (July 7), 3 (July 9), 14 (July 20), 30 (August 5), and 60 (September 4). Net photosynthetic rate (A) was measured in situ with an infrared gas analysis system (Li-6800, Li-Cor, Lincoln, NE, USA). The measurements were conducted at $1000 \mu \mathrm{mol} \mathrm{m}{ }^{-2} \mathrm{~s}^{-1}$ PAR supplied by an external LED light, which was high enough to obtain the maximum photosynthetic rate according to a pre-experiment. Gas-exchange characteristics were measured between 9:00 and 11:30 on sunny days. During the measurement, temperature, relative humidity, and $\mathrm{CO}_{2}$ concentration inside the chamber were controlled at $28{ }^{\circ} \mathrm{C}, 50 \%$, and $400 \mathrm{ppm}$, respectively. The measurements were taken both for remaining leaves and reflushing leaves.
Since the lower leaves of the TD and CK plants naturally fell after 30 days of experimental treatment, the net photosynthetic rate of the remaining leaves was not measured at day 60 . Gas exchange in the remaining leaves was measured at days 1, 3,14 , and 30 for the lower crown (TD), upper crown (BU), and both upper and lower crowns (CK). The reflushing leaves were fully expanded at day 14 after defoliation, and the gas exchange of reflushing leaves was measured at days 14, 30, and 60 for the top of the upper crown in all treatments with four replicates for each measurement. For each species, four or eight fully expanded and healthy leaves from the top of the upper crown in BU (one leaf per seedling), top of the lower crown in TD (one leaf per seedling), and both top of the upper and lower crowns in CK (two leaves per seedling) were selected from each treatment.

\subsection{Non-structural carbohydrate concentration and mass}

The leaf samples were collected at midday (12:00-15:00 h). After biomass determination, dried samples were grounded with a ball mill to quantify NSC (defined as the sum of starch and soluble sugars) concentration in the leaves, stems, and roots. Soluble sugars were extracted twice from $20 \mathrm{mg}$ of dried tissue in $5 \mathrm{ml}$ of $80 \%(\mathrm{v} / \mathrm{v})$ ethanol at $60{ }^{\circ} \mathrm{C}$. The total soluble sugar was determined by using the anthrone colorimetric method at $620 \mathrm{~nm}$ by spectrophotometry (UV9000S, Metash, Shanghai, China). Then, starch was measured after the solid residue of each sample had been extracted twice with boiling water and 9.2- $\mathrm{mol} \mathrm{L}^{-1}$ perchloric acid. The absorbance of samples was measured at $620 \mathrm{~nm}$ by spectrophotometry (UV-9000S, Metash, Shanghai, China) after an anthracenone-sulfuric acid reaction as previously described (Cao et al. 2017), and the concentrations of sugars and starch (measured as glucose equivalents) were calculated for dry mass $\left(\mathrm{mg} \mathrm{g}^{-1}\right)$. NSC mass for a given organ was calculated as the product of an individual organ's biomass and NSC concentration (mg). The soluble sugar/starch ratio (SS/ST), ratio of leaf NSC mass increment $\left(\mathrm{R}_{\mathrm{LN}}\right)$, ratio of stem NSC mass increment $\left(\mathrm{R}_{\mathrm{SN}}\right)$, ratio of root NSC mass increment $\left(\mathrm{R}_{\mathrm{RN}}\right)$, and the NSC source/sink ratio were calculated as follows:

$$
\begin{aligned}
& \frac{\mathrm{SS}}{\mathrm{ST}}=\frac{\text { Soluble sugar concentration }}{\text { Starch concentration }} \\
& \mathrm{R}_{\mathrm{LN}}=\frac{\Delta \text { Leaf NSC mass of TD }(\mathrm{BU})}{\Delta \text { Leaf NSC mass of CK }} \\
& \mathrm{R}_{\mathrm{SN}}=\frac{\Delta \text { Stem NSC mass of TD }(\mathrm{BU})}{\Delta \text { Stem NSC mass of CK }} \\
& \mathrm{R}_{\mathrm{RN}}=\frac{\Delta \text { Root NSC mass of TD }(\mathrm{BU})}{\Delta \text { Root NSC mass of CK }}
\end{aligned}
$$


NSC $\frac{\text { Source }}{\text { Sink }}=\frac{\text { Leaf NSC mass }}{\text { Stem NSC mass + Root NSC mass }}$

where $\Delta$ is the difference between NSC mass of TD (BU) at day 60 and that at day 1 . Percentage mass represents the proportion of day 1 to day 60 NSC mass.

\subsection{Statistical analysis}

Two-way analysis of variance (ANOVA) was applied to detect differences between species and defoliation treatments for every parameter. Three-way ANOVA was applied to detect differences among species, time. and defoliation treatments for NSC allocation. All ANOVAs were followed by Duncan's multiple comparison tests at $\alpha=0.05$ when significant differences were found. Before ANOVAs, data were checked for normality and homogeneity of variance. All of the statistical analyses were performed using the SPSS 23.0 software package (SPSS Inc., Chicago, IL, USA), and all figures were drawn using OriginPro 2016 (Originlab Co., Northampton, MA, USA).

\section{Results}

\subsection{Plant growth}

Generally, seedling height was not significantly different between defoliation treatments and CK in both species (Fig. 1). Considering seedlings biomass, the seedling total biomass in TD was significantly decreased at days $3-14$, and the seedling total biomass in BU significantly decreased at day 14 in
A. fruticosa (Fig. 2a). The seedling leaf biomass, stem biomass, and root biomass in TD and BU significantly decreased at day 14 in A. fruticosa (Table 1). For R. pseudoacacia, the seedling total biomass and leaf biomass in TD significantly decreased at days $1-3$, and the seedling total biomass in BU significantly decreased at day 3 (Table 1, Fig. 2b). In addition, the seedling stem biomass in TD and BU significantly decreased at day 3 compared with the CK treatment (Table 1). Especially at day 60, the root biomass increased significantly in the BU treatment compared with the CK treatment (Tables 1 and 2).

\subsection{Leaf traits}

There was no significant difference among the three defoliation treatments in A. fruticosa of the remaining leaves (Fig. 3a and b). In addition, the net photosynthetic rate in reflushing leaves was significantly higher in TD than in BU in A. fruticosa at day 30 (Fig. 4a). For R. pseudoacacia, TD and BU significantly increased the net photosynthetic rate of the remaining leaves at day 14 (Fig. 3c and d). Defoliation significantly increased the net photosynthesis of the reflushing leaves in TD at day 14 (Fig. 4b). After 30 days, defoliation treatments did not affect the net photosynthesis of the new leaves in $R$. pseudoacacia.

The total chlorophyll concentration and chlorophyll $\mathrm{a} / \mathrm{b}$ of BU increased significantly compared with that of $\mathrm{CK}$ in R. pseudoacacia (Fig. 5b and d). The SLA of BU decreased significantly compared with that of CK both in A. fruticosa and R. pseudoacacia (Fig. 5e and f). However, different defoliation treatments did not significantly affect leaf thickness in both species (Fig. $5 \mathrm{~g}$ and h).
Fig. 1 Seedling height of Amorpha fruticosa (a) and Robinia pseudoacacia (b) under different defoliation treatments. The values shown are mean $\pm \mathrm{SE}$ $(n=4)$. Different letters indicate significant differences among different defoliation treatments $(p<0.05)$ with Duncan's test. $\mathrm{CK}$, no defoliation; TD, defoliation of the top down $50 \%$ of the crown; BU, defoliation of the bottom up $50 \%$ of the crown

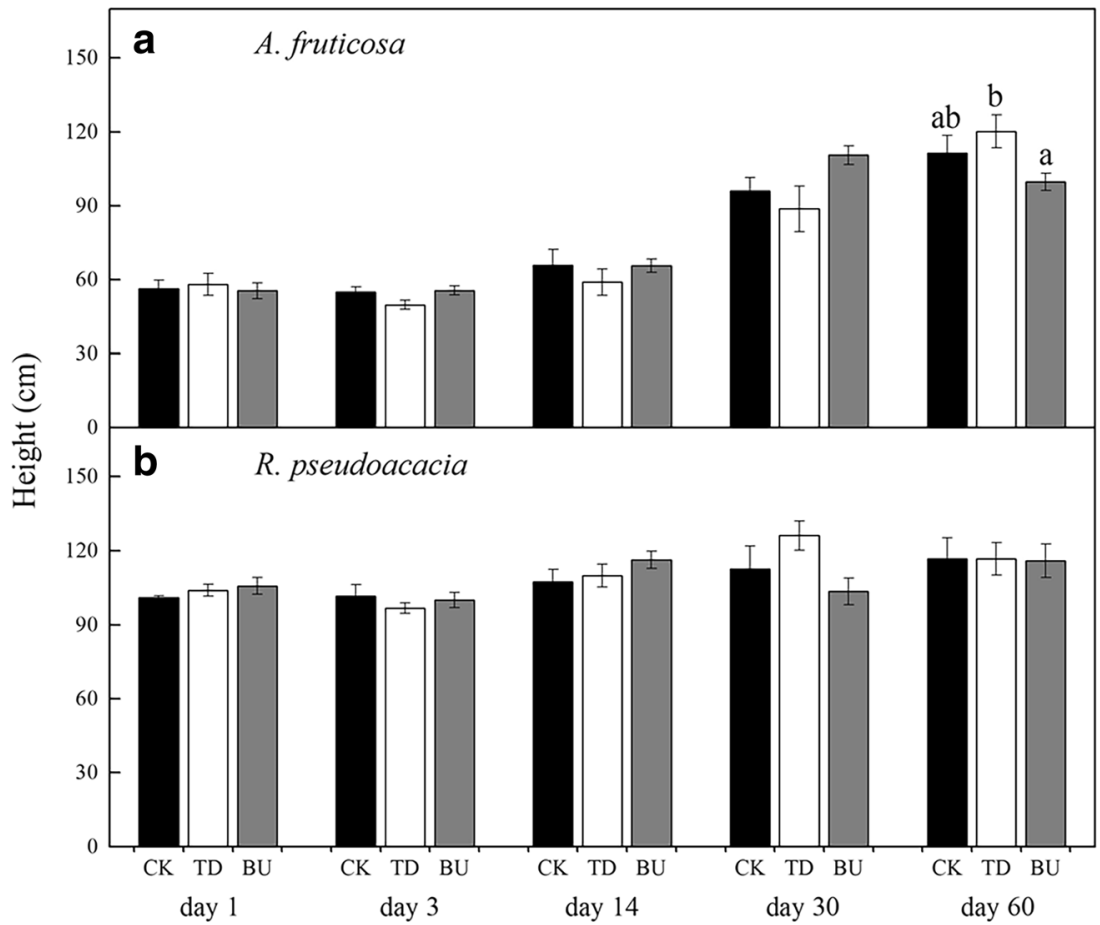

INRAC פ פ pringer 
Fig. 2 Seedling total biomass of Amorpha fruticosa (a) and Robinia pseudoacacia (b) under different defoliation treatments. The values shown are mean $\pm \mathrm{SE}$ $(n=4)$. Different letters indicate significant differences among different defoliation treatments $(p<0.05)$ with Duncan's test. CK, no defoliation; TD, defoliation of the top down $50 \%$ of the crown; BU, defoliation of the bottom up $50 \%$ of the crown

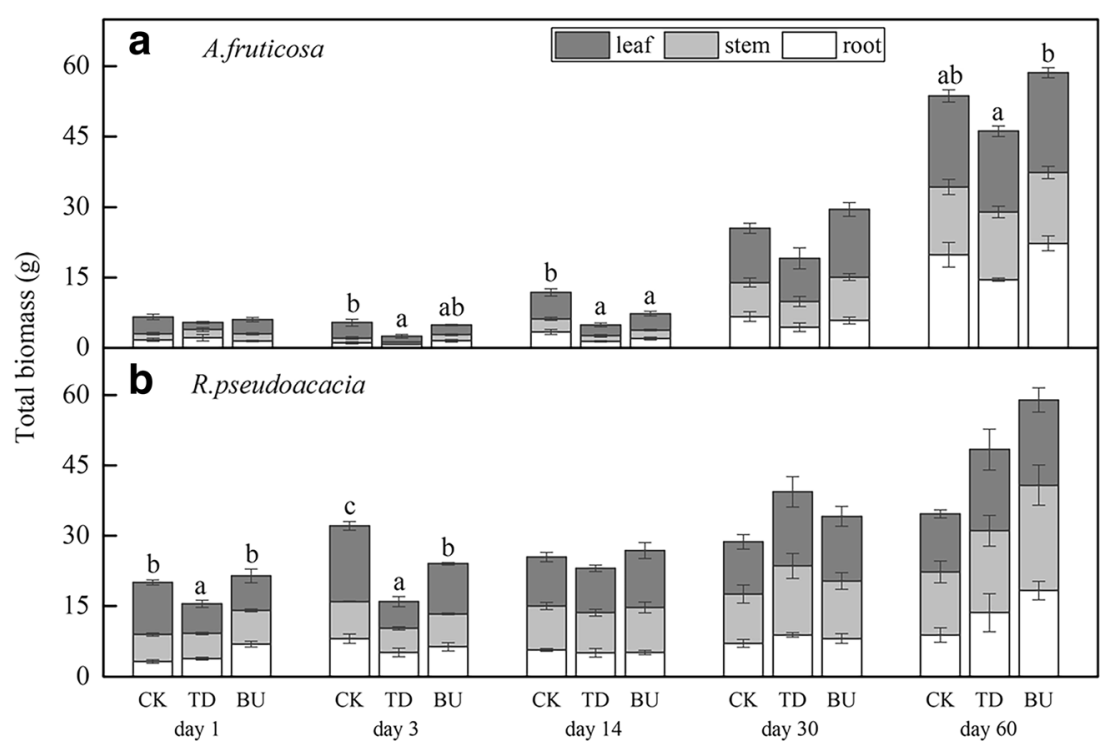

\subsection{Soluble sugar/starch ratio and NSC concentration in different defoliation treatments}

Seedling carbon allocation patterns were affected by species, time, and defoliation treatments (Table 3). The SS/ST reflects the NSC allocation pattern and can be helpful for understanding the carbohydrate-utilization strategies of plants. In this experiment, temporal changes in SS/ST ratio and NSC concentration varied by organ (Figs. 6 and 7).

For A. fruticosa, the stem SS/ST ratio in the TD treatment significantly decreased from days 1 to 3 , and the stem SS/ST ratio in the $\mathrm{BU}$ treatment significantly decreased at day 3 (Fig. 7c). The stem NSC concentration and soluble sugar concentration in TD and BU treatments significantly decreased at day
Table 1 Biomass (mean \pm SE) of Amorpha fruticosa and Robinia pseudoacacia seedlings harvested at days 1 (July 7), 3 (July 9), 14 (July 20), 30 (August 5), and 60 (September 4). Different lowercase letters indicate significant differences among different defoliation treatments $(p<0.05)$ with Duncan's test

\begin{tabular}{|c|c|c|c|c|c|c|c|}
\hline \multirow[t]{3}{*}{ Organ } & \multirow[t]{3}{*}{ Date } & \multicolumn{6}{|c|}{ Biomass by treatment $(\mathrm{g})$} \\
\hline & & \multicolumn{3}{|c|}{ Amorpha fruticosa } & \multicolumn{3}{|c|}{ Robinia pseudoacacia } \\
\hline & & CK & $\mathrm{TD}$ & $\mathrm{BU}$ & $\mathrm{CK}$ & $\mathrm{TD}$ & $\mathrm{BU}$ \\
\hline \multirow[t]{5}{*}{ Leaf } & Day 1 & $3.56 \pm 0.56^{\mathrm{b}}$ & $1.50 \pm 0.24^{\mathrm{a}}$ & $3.00 \pm 0.44^{\mathrm{b}}$ & $11.02 \pm 0.54^{\mathrm{b}}$ & $6.20 \pm 0.77^{\mathrm{a}}$ & $7.35 \pm 1.49^{\mathrm{a}}$ \\
\hline & Day 3 & $3.26 \pm 0.73^{\mathrm{ab}}$ & $1.22 \pm 0.40^{\mathrm{a}}$ & $2.01 \pm 0.16^{\mathrm{b}}$ & $16.17 \pm 0.93^{\mathrm{c}}$ & $5.63 \pm 1.09^{\mathrm{a}}$ & $10.70 \pm 0.24^{\mathrm{b}}$ \\
\hline & Day 14 & $5.60 \pm 0.76^{\mathrm{b}}$ & $2.28 \pm 0.41^{\mathrm{a}}$ & $3.48 \pm 0.52^{\mathrm{a}}$ & $10.43 \pm 0.97^{\mathrm{a}}$ & $9.48 \pm 0.69^{\mathrm{a}}$ & $12.11 \pm 1.69^{\mathrm{a}}$ \\
\hline & Day 30 & $11.57 \pm 1.10^{\mathrm{a}}$ & $9.20 \pm 2.23^{\mathrm{a}}$ & $14.45 \pm 1.48^{\mathrm{a}}$ & $11.19 \pm 1.55^{\mathrm{a}}$ & $15.81 \pm 3.28^{\mathrm{a}}$ & $13.82 \pm 2.15^{\mathrm{a}}$ \\
\hline & Day 60 & $19.33 \pm 1.35^{\mathrm{ab}}$ & $17.16 \pm 1.13^{\mathrm{a}}$ & $21.17 \pm 1.10^{\mathrm{b}}$ & $12.36 \pm 0.88^{\mathrm{a}}$ & $17.33 \pm 4.38^{\mathrm{a}}$ & $18.15 \pm 2.60^{\mathrm{a}}$ \\
\hline \multirow[t]{5}{*}{ Stem } & Day 1 & $1.30 \pm 0.27^{\mathrm{a}}$ & $1.77 \pm 0.42^{\mathrm{a}}$ & $1.56 \pm 0.24^{\mathrm{a}}$ & $5.75 \pm 0.36^{\mathrm{a}}$ & $5.39 \pm 0.28^{\mathrm{a}}$ & $7.12 \pm 0.31^{\mathrm{b}}$ \\
\hline & Day 3 & $1.05 \pm 0.27^{\mathrm{ab}}$ & $0.47 \pm 0.10^{\mathrm{a}}$ & $1.32 \pm 0.19^{\mathrm{b}}$ & $7.83 \pm 0.13^{\mathrm{c}}$ & $5.14 \pm 0.32^{\mathrm{b}}$ & $6.91 \pm 0.19^{\mathrm{a}}$ \\
\hline & Day 14 & $2.80 \pm 0.37^{\mathrm{b}}$ & $1.21 \pm 0.25^{\mathrm{a}}$ & $1.78 \pm 0.20^{\mathrm{a}}$ & $9.29 \pm 0.74^{\mathrm{a}}$ & $8.48 \pm 0.75^{\mathrm{a}}$ & $9.51 \pm 1.18^{\mathrm{a}}$ \\
\hline & Day 30 & $7.27 \pm 0.96^{\mathrm{ab}}$ & $5.48 \pm 1.09^{\mathrm{a}}$ & $9.25 \pm 0.73^{\mathrm{b}}$ & $10.42 \pm 1.93^{\mathrm{a}}$ & $14.62 \pm 2.69^{\mathrm{a}}$ & $12.16 \pm 1.77^{\mathrm{a}}$ \\
\hline & Day 60 & $14.48 \pm 1.64^{\mathrm{a}}$ & $14.43 \pm 1.22^{\mathrm{a}}$ & $15.13 \pm 1.32^{\mathrm{a}}$ & $13.40 \pm 2.31^{\mathrm{a}}$ & $17.44 \pm 3.26^{\mathrm{a}}$ & $22.47 \pm 4.27^{\mathrm{a}}$ \\
\hline \multirow[t]{5}{*}{ Root } & Day 1 & $1.71 \pm 0.33^{\mathrm{a}}$ & $2.14 \pm 0.67^{\mathrm{a}}$ & $1.46 \pm 0.18^{\mathrm{a}}$ & $3.29 \pm 0.37^{\mathrm{a}}$ & $3.88 \pm 0.33^{\mathrm{a}}$ & $6.97 \pm 0.64^{\mathrm{b}}$ \\
\hline & Day 3 & $1.06 \pm 0.26^{\mathrm{ab}}$ & $0.76 \pm 0.11^{\mathrm{a}}$ & $1.51 \pm 0.27^{\mathrm{b}}$ & $8.13 \pm 1.03^{\mathrm{a}}$ & $5.20 \pm 0.95^{\mathrm{a}}$ & $6.43 \pm 0.89^{a}$ \\
\hline & Day 14 & $3.39 \pm 0.57^{\mathrm{b}}$ & $1.37 \pm 0.14^{\mathrm{a}}$ & $2.02 \pm 0.31^{\mathrm{a}}$ & $5.73 \pm 0.33^{\mathrm{a}}$ & $5.11 \pm 0.93^{\mathrm{a}}$ & $5.21 \pm 0.44^{\mathrm{a}}$ \\
\hline & Day 30 & $6.66 \pm 1.03^{\mathrm{a}}$ & $4.41 \pm 0.93^{\mathrm{a}}$ & $5.82 \pm 0.76^{\mathrm{a}}$ & $7.11 \pm 0.86^{\mathrm{a}}$ & $8.94 \pm 0.51^{\mathrm{a}}$ & $8.16 \pm 1.06^{\mathrm{a}}$ \\
\hline & Day 60 & $19.83 \pm 2.64^{\mathrm{ab}}$ & $14.54 \pm 0.37^{\mathrm{a}}$ & $22.28 \pm 1.56^{\mathrm{b}}$ & $8.90 \pm 1.53^{\mathrm{a}}$ & $13.62 \pm 4.03^{\mathrm{ab}}$ & $18.32 \pm 1.98^{b}$ \\
\hline
\end{tabular}

$C K$, no defoliation; $T D$, defoliation of the top down $50 \%$ of the crown; $B U$, defoliation of the bottom up $50 \%$ of the crown $n=4$ 
Table 2 Non-structural carbohydrate (NSC) mass (mean \pm SE) in Amorpha fruticosa and Robinia pseudoacacia seedlings was harvested at days 1 (July 7), 3 (July 9), 14 (July 20), 30 (August 5), and 60
(September 4). Different lowercase letters indicate significant differences among different defoliation treatments $(p<0.05)$ with Duncan's test

\begin{tabular}{|c|c|c|c|c|c|c|c|}
\hline \multirow[t]{3}{*}{ Organ } & \multirow[t]{3}{*}{ Date } & \multicolumn{6}{|c|}{ NSC mass by treatment (g) } \\
\hline & & \multicolumn{3}{|c|}{ Amorpha fruticosa } & \multicolumn{3}{|c|}{ Robinia pseudoacacia } \\
\hline & & CK & $\mathrm{TD}$ & $\mathrm{BU}$ & $\mathrm{CK}$ & TD & BU \\
\hline \multirow[t]{6}{*}{ Leaf } & Day 1 & $0.32 \pm 0.06^{\mathrm{a}}$ & $0.14 \pm 0.03^{\mathrm{a}}$ & $0.28 \pm 0.06^{\mathrm{a}}$ & $1.42 \pm 0.08^{\mathrm{b}}$ & $0.63 \pm 0.13^{\mathrm{a}}$ & $0.91 \pm 0.20^{\mathrm{ab}}$ \\
\hline & Day 3 & $0.53 \pm 0.11^{\mathrm{b}}$ & $0.21 \pm 0.09^{\mathrm{a}}$ & $0.33 \pm 0.03^{\mathrm{ab}}$ & $1.17 \pm 0.18^{\mathrm{ab}}$ & $0.78 \pm 0.11^{\mathrm{a}}$ & $1.52 \pm 0.16^{\mathrm{b}}$ \\
\hline & Day 14 & $0.42 \pm 0.04^{\mathrm{b}}$ & $0.18 \pm 0.05^{\mathrm{a}}$ & $0.24 \pm 0.04^{\mathrm{a}}$ & $1.65 \pm 0.21^{\mathrm{a}}$ & $1.44 \pm 0.10^{\mathrm{a}}$ & $1.64 \pm 0.10^{\mathrm{a}}$ \\
\hline & Day 30 & $1.57 \pm 0.28^{\mathrm{a}}$ & $1.24 \pm 0.33^{\mathrm{a}}$ & $1.96 \pm 0.14^{\mathrm{a}}$ & $1.72 \pm 0.13^{\mathrm{a}}$ & $1.69 \pm 0.29^{\mathrm{a}}$ & $1.78 \pm 0.12^{\mathrm{a}}$ \\
\hline & Day 60 & $2.24 \pm 0.35^{\mathrm{a}}$ & $2.32 \pm 0.41^{\mathrm{a}}$ & $3.00 \pm 0.31^{\mathrm{a}}$ & $1.63 \pm 0.10^{\mathrm{a}}$ & $1.94 \pm 0.52^{\mathrm{a}}$ & $1.96 \pm 0.21^{\mathrm{a}}$ \\
\hline & $\mathrm{R}_{\mathrm{LN}}$ & 1.00 & 1.14 & 1.42 & 1.00 & 6.24 & 5.00 \\
\hline \multirow[t]{6}{*}{ Stem } & Day 1 & $0.09 \pm 0.03^{\mathrm{a}}$ & $0.08 \pm 0.02^{\mathrm{a}}$ & $0.07 \pm 0.11^{\mathrm{a}}$ & $0.47 \pm 0.02^{\mathrm{a}}$ & $0.28 \pm 0.04^{\mathrm{a}}$ & $0.47 \pm 0.10^{\mathrm{a}}$ \\
\hline & Day 3 & $0.08 \pm 0.04^{\mathrm{a}}$ & $0.01 \pm 0.00^{\mathrm{a}}$ & $0.04 \pm 0.01^{\mathrm{a}}$ & $0.81 \pm 0.06^{\mathrm{b}}$ & $0.37 \pm 0.02^{\mathrm{a}}$ & $0.22 \pm 0.05^{\mathrm{a}}$ \\
\hline & Day 14 & $0.09 \pm 0.01^{\mathrm{c}}$ & $0.03 \pm 0.00^{\mathrm{a}}$ & $0.05 \pm 0.009^{\mathrm{b}}$ & $0.76 \pm 0.17^{\mathrm{a}}$ & $0.62 \pm 0.14^{\mathrm{a}}$ & $0.67 \pm 0.08^{\mathrm{a}}$ \\
\hline & Day 30 & $0.23 \pm 0.04^{\mathrm{a}}$ & $0.25 \pm 0.05^{\mathrm{a}}$ & $0.40 \pm 0.10^{\mathrm{a}}$ & $0.70 \pm 0.10^{\mathrm{a}}$ & $0.80 \pm 0.21^{\mathrm{a}}$ & $0.65 \pm 0.16^{\mathrm{a}}$ \\
\hline & Day 60 & $0.53 \pm 0.12^{\mathrm{a}}$ & $0.51 \pm 0.06^{\mathrm{a}}$ & $0.63 \pm 0.11^{\mathrm{a}}$ & $0.74 \pm 0.16^{\mathrm{a}}$ & $1.03 \pm 0.30^{\mathrm{a}}$ & $1.10 \pm 0.28^{\mathrm{a}}$ \\
\hline & $\mathrm{R}_{\mathrm{SN}}$ & 1.00 & 0.98 & 1.27 & 1.00 & 2.78 & 2.33 \\
\hline \multirow[t]{6}{*}{ Root } & Day 1 & $0.20 \pm 0.04^{\mathrm{a}}$ & $0.16 \pm 0.08^{\mathrm{a}}$ & $0.14 \pm 0.04^{\mathrm{a}}$ & $0.17 \pm 0.02^{\mathrm{a}}$ & $0.21 \pm 0.04^{\mathrm{a}}$ & $0.33 \pm 0.08^{\mathrm{a}}$ \\
\hline & Day 3 & $0.08 \pm 0.02^{\mathrm{a}}$ & $0.03 \pm 0.01^{\mathrm{a}}$ & $0.11 \pm 0.04^{\mathrm{a}}$ & $0.80 \pm 0.11^{\mathrm{b}}$ & $0.456 \pm 0.142^{\mathrm{ab}}$ & $0.417 \pm 0.061^{\mathrm{a}}$ \\
\hline & Day 14 & $0.13 \pm 0.02^{\mathrm{b}}$ & $0.05 \pm 0.01^{\mathrm{a}}$ & $0.079 \pm 0.00^{\mathrm{a}}$ & $0.65 \pm 0.11^{\mathrm{a}}$ & $0.54 \pm 0.12^{\mathrm{a}}$ & $0.34 \pm 0.04^{\mathrm{a}}$ \\
\hline & Day 30 & $0.72 \pm 0.16^{\mathrm{a}}$ & $0.64 \pm 0.20^{\mathrm{a}}$ & $0.66 \pm 0.09^{\mathrm{a}}$ & $0.58 \pm 0.14^{\mathrm{a}}$ & $0.77 \pm 0.13^{\mathrm{a}}$ & $0.59 \pm 0.05^{\mathrm{a}}$ \\
\hline & Day 60 & $2.21 \pm 0.43^{\mathrm{a}}$ & $1.47 \pm 0.18^{\mathrm{a}}$ & $1.87 \pm 0.52^{\mathrm{a}}$ & $1.55 \pm 0.36^{\mathrm{a}}$ & $1.98 \pm 0.69^{\mathrm{a}}$ & $3.01 \pm 0.54^{\mathrm{a}}$ \\
\hline & $\mathrm{R}_{\mathrm{RN}}$ & 1.00 & 0.65 & 0.86 & 1.00 & 1.28 & 1.94 \\
\hline \multirow[t]{6}{*}{ Total } & Day 1 & $0.61 \pm 0.13^{\mathrm{a}}$ & $0.38 \pm 0.12^{\mathrm{a}}$ & $0.50 \pm 0.10^{\mathrm{a}}$ & $2.06 \pm 0.10^{\mathrm{b}}$ & $1.12 \pm 0.17^{\mathrm{a}}$ & $1.71 \pm 0.11^{\mathrm{b}}$ \\
\hline & Day 3 & $0.68 \pm 0.15^{\mathrm{b}}$ & $0.25 \pm 0.08^{\mathrm{a}}$ & $0.47 \pm 0.06^{\mathrm{ab}}$ & $2.77 \pm 0.32^{\mathrm{b}}$ & $1.61 \pm 0.26^{\mathrm{a}}$ & $2.17 \pm 0.26^{\mathrm{ab}}$ \\
\hline & Day 14 & $0.65 \pm 0.06^{\mathrm{b}}$ & $0.25 \pm 0.06^{\mathrm{a}}$ & $0.38 \pm 0.05^{\mathrm{a}}$ & $3.07 \pm 0.45^{\mathrm{a}}$ & $2.60 \pm 0.20^{\mathrm{a}}$ & $2.79 \pm 0.24^{\mathrm{a}}$ \\
\hline & Day 30 & $2.51 \pm 0.19^{\mathrm{a}}$ & $2.12 \pm 0.56^{\mathrm{a}}$ & $2.98 \pm 0.22^{\mathrm{a}}$ & $3.00 \pm 0.17^{\mathrm{a}}$ & $3.26 \pm 0.53^{\mathrm{a}}$ & $3.17 \pm 0.32^{\mathrm{a}}$ \\
\hline & Day 60 & $4.98 \pm 0.81^{\mathrm{a}}$ & $4.30 \pm 0.42^{\mathrm{a}}$ & $5.50 \pm 0.61^{\mathrm{a}}$ & $3.72 \pm 0.39^{\mathrm{a}}$ & $4.95 \pm 1.44^{\mathrm{a}}$ & $6.07 \pm 0.94^{\mathrm{a}}$ \\
\hline & Percentage mass & $12 \%$ & $9 \%$ & $9 \%$ & $55 \%$ & $23 \%$ & $28 \%$ \\
\hline
\end{tabular}

Percentage mass represents the proportion of day 1 to day 60 NSC mass

$R_{L N}$, ratio of leaf NSC mass increment; $R_{R N}$, ratio of root NSC mass increment; $R_{S N}$, ratio of stem NSC mass increment; $C K$, no defoliation; $T D$, defoliation of the top down $50 \%$ of the crown; $B U$, defoliation of the bottom up $50 \%$ of the crown

$n=4$

3 (Fig. 6c). The stem starch concentration and NSC concentration in the TD treatment of A. fruticosa significantly decreased at day 14 (Fig. 6c). The root NSC concentration and soluble sugar concentration in the TD treatment significantly decreased at day 1 (Fig. 6e). The starch concentration in roots was relatively stable, and there was no significant difference among defoliation treatments of starch concentration during the experiment period (Fig. 6e).

It is different in $R$. pseudoacacia, the stem SS/ST ratio significantly decreased at day 1 in both TD and BU treatments and at day 3 in the BU treatment (Fig. 7d). The stem NSC concentration, soluble sugar concentration, and starch concentration in TD and BU treatments significantly decreased at day 3 (Fig. 6d). The root NSC concentration and soluble sugar concentration in the BU treatment significantly decreased at days $3-14$, and the NSC concentration in TD significantly decreased at day 14, in R. pseudoacacia (Fig. 6f).

\subsection{NSC mass changes}

For A. fruticosa, NSC mass in TD was significantly lower than CK from days 3 to 14 (Table 2), NSC mass in BU was also significantly lower than CK at day 14 (Table 2). For $R$. pseudoacacia, NSC mass in TD was significantly lower than CK from days 1 to 3 , and BU significantly decreased at day 3 (Table 2). In addition, the NSC mass of R. pseudoacacia recovered by day 14 , whereas that of $A$. fruticosa recovered by day 30 after defoliation. 
Fig. 3 Net photosynthetic rate of remaining leaves $\left(\mathrm{A}_{\mathrm{REM}}\right)$ of Amorpha fruticosa $(\mathrm{a}, \mathrm{b})$ and Robinia pseudoacacia (c, d) under different defoliation treatments. The values shown are mean $\pm \mathrm{SE}(n=4)$. The asterisk represents the significant difference $(p<0.05)$ between the control group and the defoliation group; CK, no defoliation; TD, defoliation of the top down $50 \%$ of the crown; BU, defoliation of the bottom up $50 \%$ of the crown. $\mathrm{CK}$ in a and c, upper leaves in the crown were measured, whereas $b$ and $\mathrm{d}$ concerned lower leaves

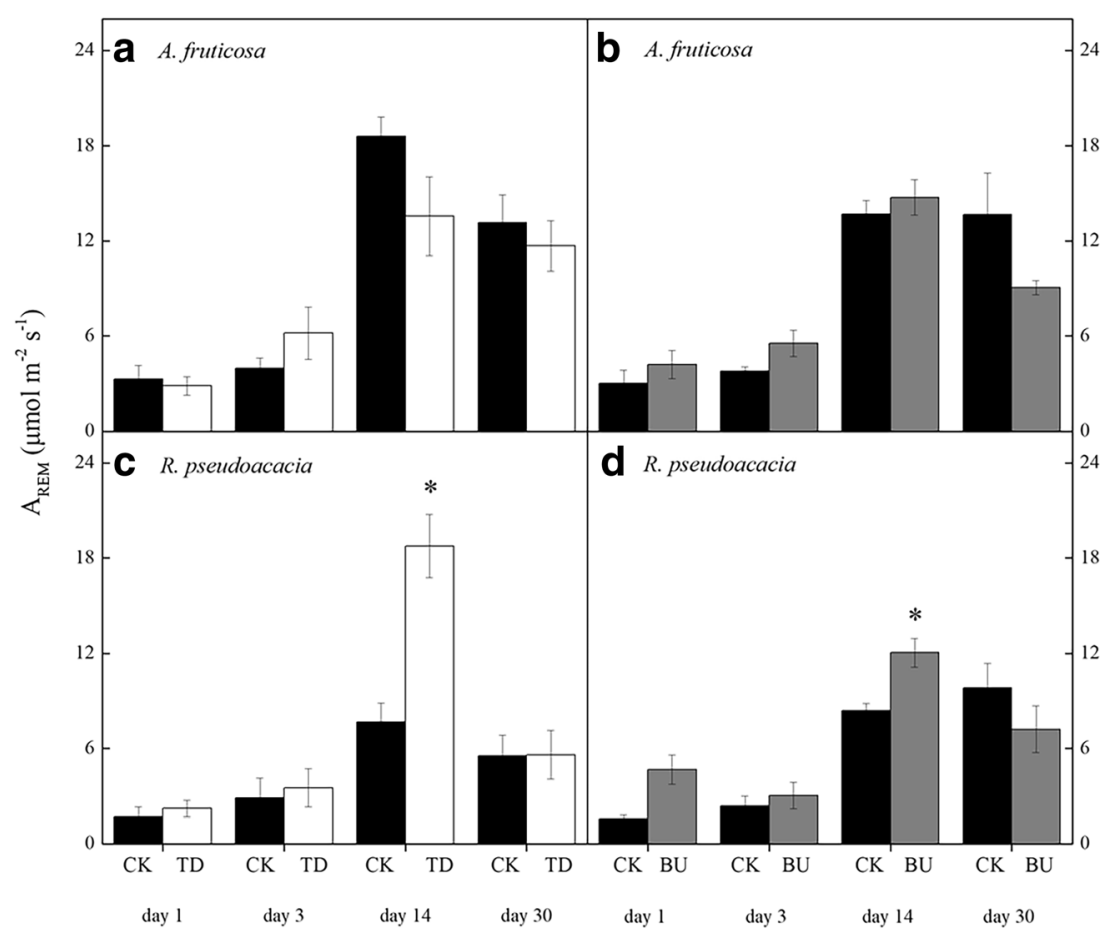

For A. fruticosa, the ratio of leaf NSC mass increment $\left(\mathrm{R}_{\mathrm{LN}}\right)$ was indicated $14 \%$ higher in the TD treatment and $42 \%$ higher in the BU treatment than $\mathrm{CK}$ (Table 2). The ratio of stem NSC mass increment $\left(\mathrm{R}_{\mathrm{SN}}\right)$ was indicated $2 \%$ lower in the TD treatment and $27 \%$ higher in the BU treatment than $\mathrm{CK}$. However, the ratio of root NSC mass increment $\left(\mathrm{R}_{\mathrm{RN}}\right)$ was indicated $35 \%$ lower in the TD treatment and $14 \%$ lower in the BU treatment than $\mathrm{CK}$. In addition, the ratio of stem NSC mass increment in the TD treatment of $A$. fruticosa was lower than that in the BU treatment during the experiment. For $R$. pseudoacacia, $\mathrm{R}_{\mathrm{LN}}, \mathrm{R}_{\mathrm{SN}}$, and $\mathrm{R}_{\mathrm{RN}}$ in the TD treatment were indicated $524 \%$, $178 \%$, and $28 \%$ higher than $\mathrm{CK}$, respectively. $\mathrm{R}_{\mathrm{LN}}$, $\mathrm{R}_{\mathrm{SN}}$ and $\mathrm{R}_{\mathrm{RN}}$ in the $\mathrm{BU}$ treatment were indicated $400 \%, 133 \%$, and $94 \%$ higher than CK (Table 2).
Fig. 4 Net photosynthetic rate of reflushing leaves $\left(\mathrm{A}_{\mathrm{REF}}\right)$ of Amorpha fruticosa (a) and Robinia pseudoacacia (b) under different defoliation treatments. The values shown are mean $\pm \mathrm{SE}$ $(n=4)$. Different letters indicate significant differences among different defoliation treatments $(p<0.05)$ with Duncan's test. CK, no defoliation; TD, defoliation of the top down $50 \%$ of the crown; BU, defoliation of the bottom up $50 \%$ of the crown

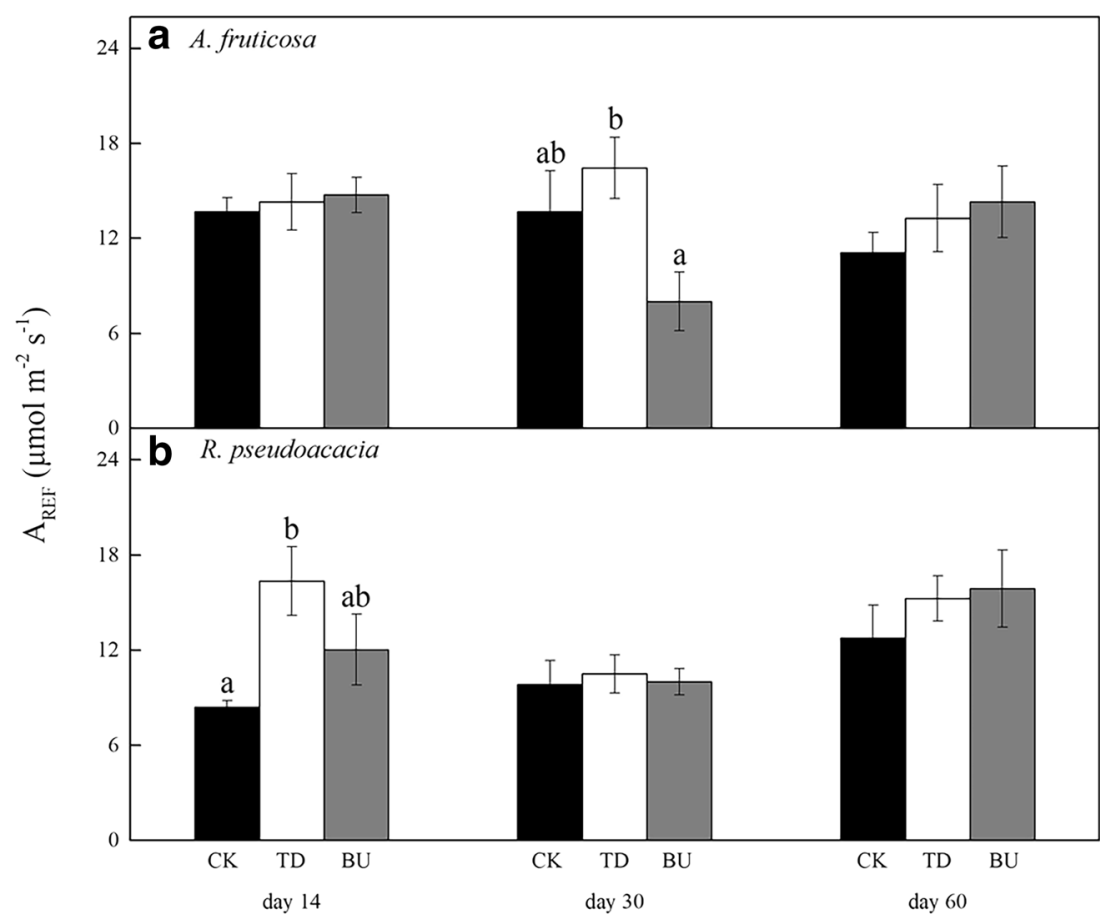


Fig. 5 Seedling total chlorophyll concentration, chlorophyll a/b, leaf thickness, and specific leaf area (SLA) of Amorpha fruticosa (a, c, e, g) and Robinia pseudoacacia $(\mathrm{b}, \mathrm{d}, \mathrm{f}, \mathrm{h})$ under different defoliation position treatments at day 60 . The values shown are mean $\pm \operatorname{SE}(n=3-4)$. Different letters indicate significant differences among different defoliation treatments $(p<0.05)$ with Duncan's test.

$\mathrm{CK}$, no defoliation; TD,

defoliation of the top down $50 \%$ of the crown; BU, defoliation of the bottom up $50 \%$ of the crown

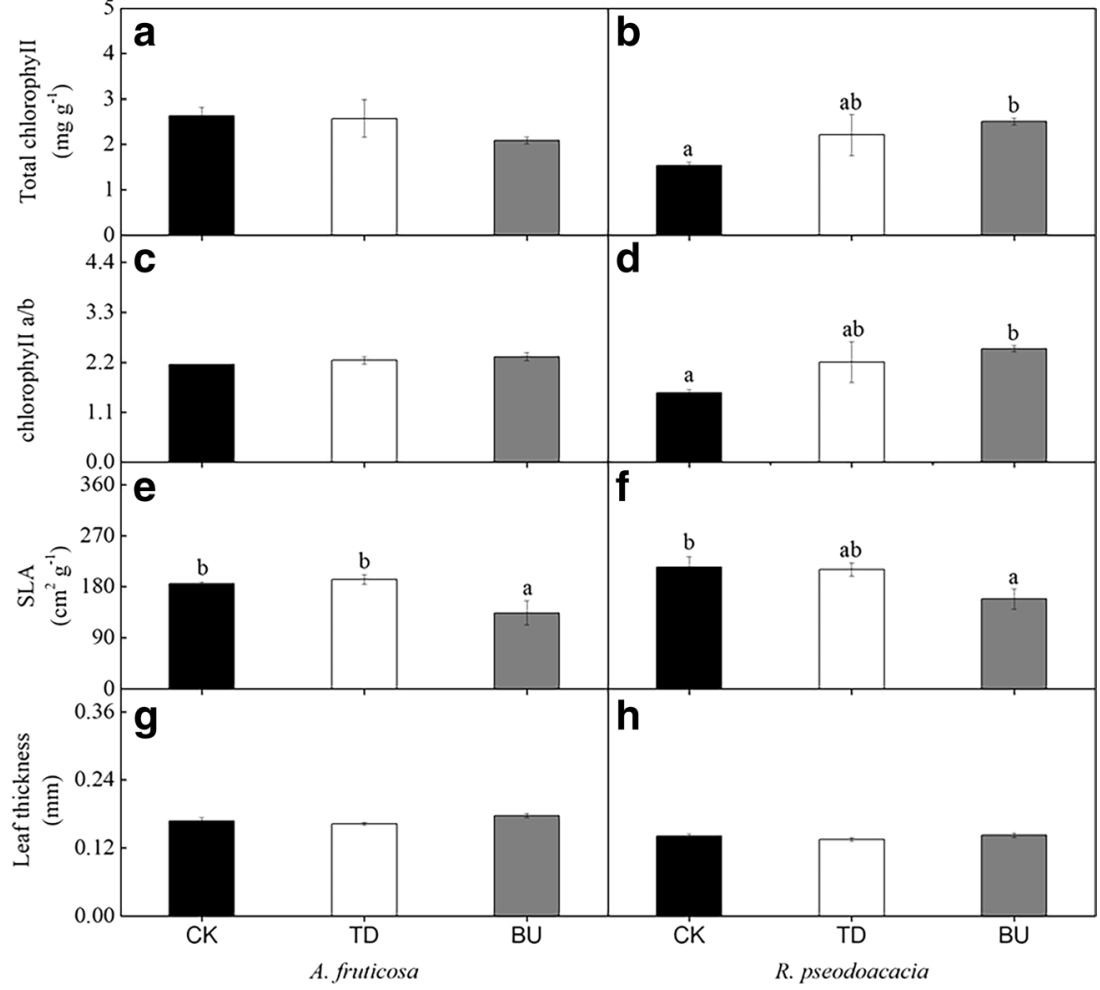

\subsection{Temporal changes in NSC source/sink ratio}

At the beginning of the experiment, $50 \%$ of seedling leaves were removed, which decreased the NSC source/ sink ratio in $R$. pseudoacacia but not in A. fruticosa (Fig. 8). This may be related to the small size of the seedlings when the leaves were removed. Defoliation treatment did not significantly affect NSC source/sink ratio in the TD treatment and the BU treatment of A. fruticosa (Fig. 8a). For R. pseudoacacia, the NSC source/sink in the BU treatment was significantly higher than that of CK at days 3-14 (Fig. 8b). The NSC source/ sink ranged between 0.74 and 6.01 in A. fruticosa and between 0.53 and 2.45 in $R$. pseudoacacia.
Table $3 F$ values of three-way ANOVA in different treatments on A. fruticosa and R. pseudoacacia

\begin{tabular}{|c|c|c|c|c|c|c|c|}
\hline Parameters & $\mathrm{S}$ & $\mathrm{D}$ & $\mathrm{T}$ & $\mathrm{S} \times \mathrm{D}$ & $\mathrm{S} \times \mathrm{T}$ & $\mathrm{D} \times \mathrm{T}$ & $\mathrm{S} \times \mathrm{D} \times \mathrm{T}$ \\
\hline Height (cm) & $296.48 * * *$ & 0.04 & $60.03 * * *$ & 0.68 & $22.81 * * *$ & 0.97 & $2.80 * *$ \\
\hline Leaf SS/ST & $5.79 *$ & $3.12 *$ & $54.65 * * *$ & 1.98 & $2.54 *$ & 1.39 & $3.49 * *$ \\
\hline Stem SS/ST & $5.48^{*}$ & $3.22 *$ & $8.60 * * *$ & 0.35 & $2.68 *$ & $5.57 * * *$ & 1.43 \\
\hline Root SS/ST & 3.95 & 0.75 & $12.24 * * *$ & 0.03 & $7.65 * * *$ & $3.46^{* *}$ & 1.03 \\
\hline $\begin{array}{l}\text { Leaf concentration } \\
\qquad\left(\mathrm{mg} \mathrm{g}^{-1}\right)\end{array}$ & $4.62 *$ & 1.07 & $10.93 * * *$ & 0.63 & $18.78 * * *$ & 0.58 & 0.61 \\
\hline $\begin{array}{l}\text { Stem concentration } \\
\qquad\left(\mathrm{mg} \mathrm{g}^{-1}\right)\end{array}$ & $70.01 * * *$ & $11.91 * * *$ & 2.25 & 2.52 & $3.90 * *$ & $4.57 * * *$ & 1.02 \\
\hline $\begin{array}{l}\text { Root concentration } \\
\qquad\left(\mathrm{mg} \mathrm{g}^{-1}\right)\end{array}$ & $9.31 * *$ & $5.79 * *$ & $21.98 * * *$ & 0.70 & $21.86 * * *$ & $2.06^{*}$ & 1.90 \\
\hline Leaf biomass (g) & $50.40 * * *$ & $5.59 * *$ & $68.73 * * *$ & 0.38 & $14.63 * * *$ & $2.94 * *$ & $2.86 * *$ \\
\hline Stem biomass (g) & $96.99 * * *$ & 2.89 & $83.61 * * *$ & 1.26 & 1.66 & 1.31 & 1.71 \\
\hline Root biomass (g) & $15.99 * * *$ & $6.11 * *$ & $126.84 * * *$ & $5.58 *$ & $17.73 * * *$ & $3.52 * *$ & $2.46^{*}$ \\
\hline
\end{tabular}

$S$, species; $D$, defoliation treatment; $T$, time

$* p<0.05$

$* * p<0.01$

$* * * p<0.001$

$n=4$ 


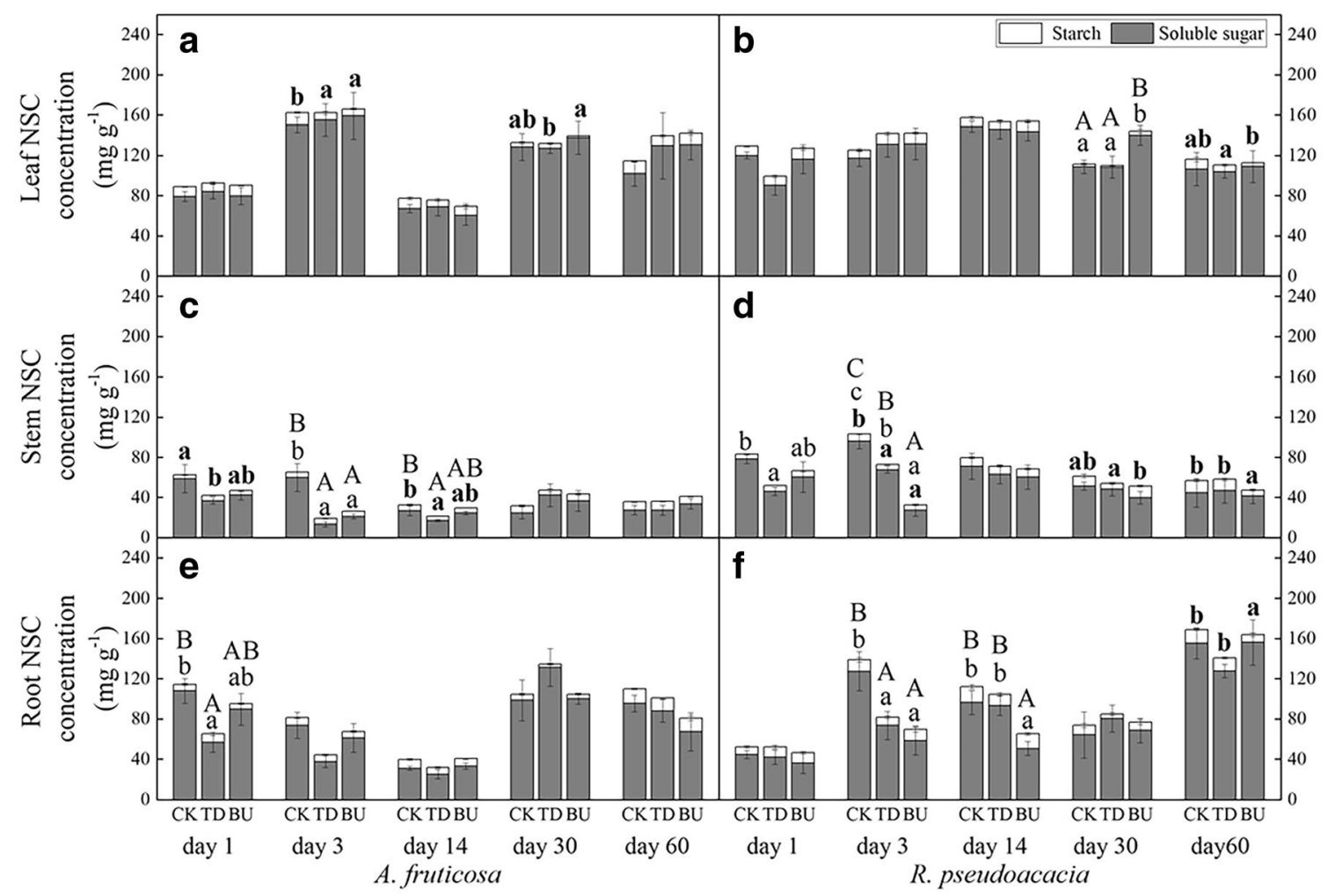

Fig. 6 NSC concentration represents the sum of soluble sugar and starch concentrations measured in three compartments (leaf, stem, root) of Amorpha fruticosa (a, c, e) and Robinia pseudoacacia (b, d, f) under different defoliation treatments through time. The values shown are mean \pm SE $(n=4)$. Different letters indicate significant differences among different defoliation treatments $(p<0.05)$ with Duncan's test.
Lowercase letters without bold are used for soluble sugar concentration. Lowercase letters with bold are used for starch concentration. Uppercase letters are used for NSC concentration. CK, no defoliation; TD, defoliation of the top down $50 \%$ of the crown; BU, defoliation of the bottom up $50 \%$ of the crown
Fig. 7 Soluble sugar/starch (SS/ ST) ratio concerned three compartments (leaf, stem, root) of Amorpha fruticosa (a, c, e) and Robinia pseudoacacia (b, d, f) under different defoliation treatments through time. The values shown are mean $\pm \mathrm{SE}$ $(n=4)$. Different letters indicate significant differences among different defoliation treatments $(p<0.05)$ with Duncan's test. CK, no defoliation; TD, defoliation of the top down $50 \%$ of the crown; BU, defoliation of the bottom up $50 \%$ of the crown

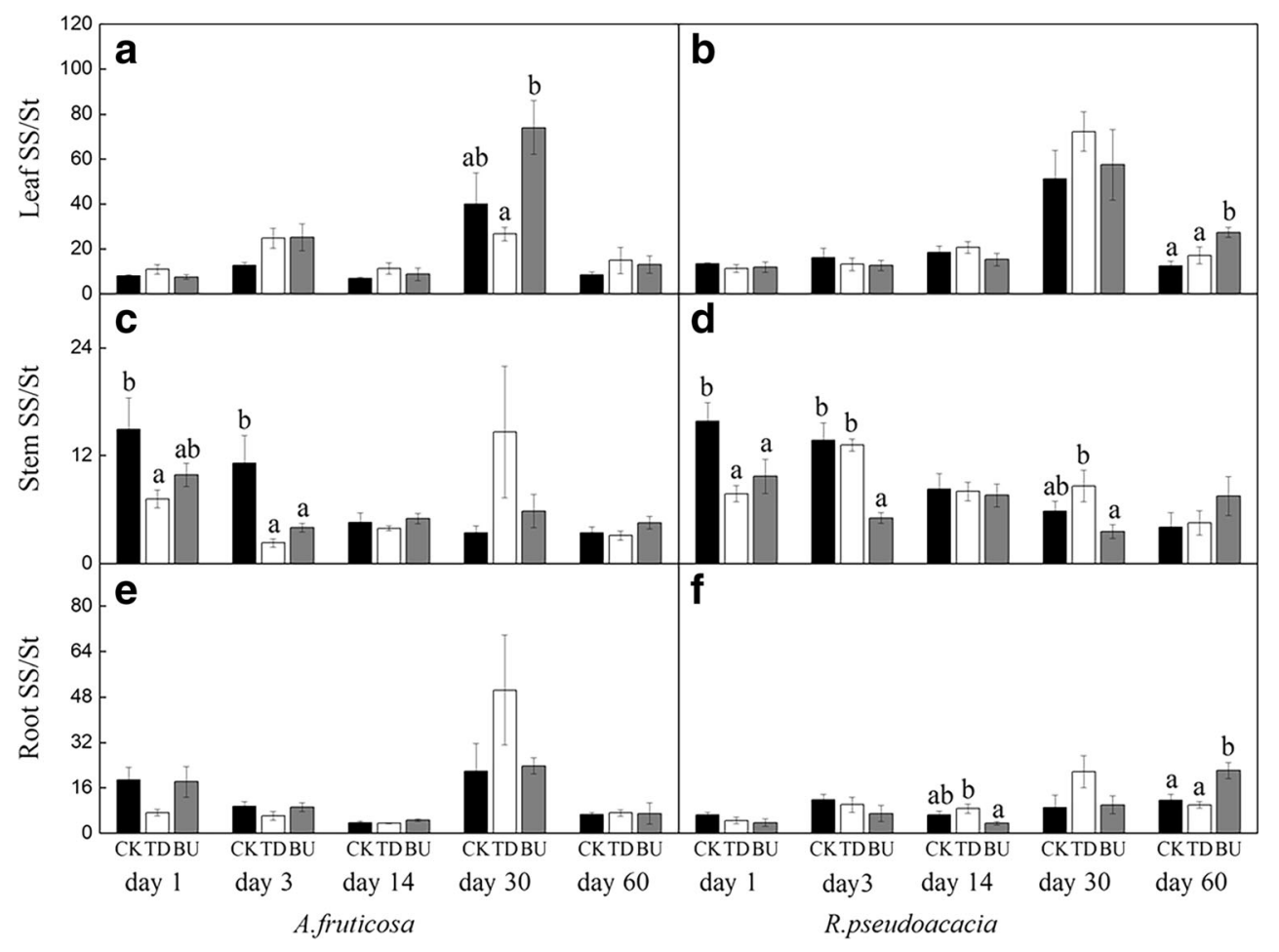


Fig. 8 The source/sink ratio of Amorpha fruticosa and Robinia pseudoacacia under different defoliation treatments through time. The values shown are mean $\pm \mathrm{SE}(n=4)$. Different letters indicate significant differences among different defoliation treatments $(p<0.05)$ with Duncan's test. CK, no defoliation; $\mathrm{TD}$, defoliation of the top down $50 \%$ of the crown; $\mathrm{BU}$, defoliation of the bottom up 50\% of the crown

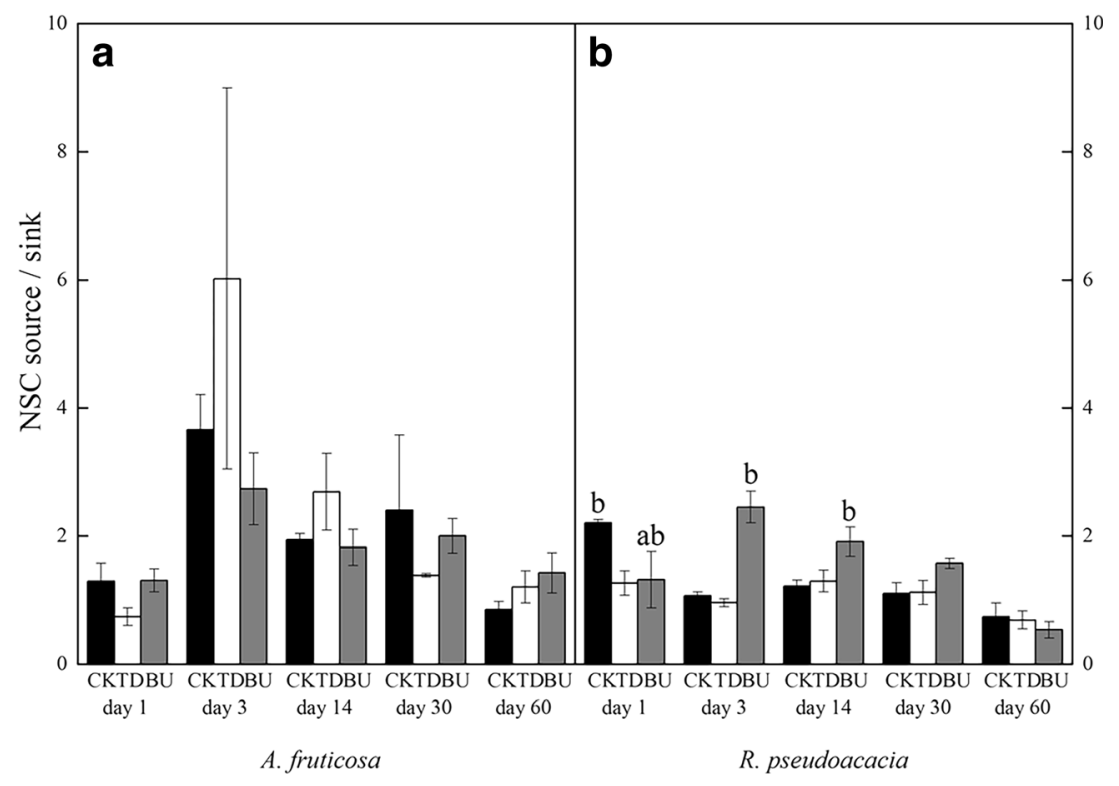

\section{Discussion}

\subsection{Effects of defoliation on $A$. fruticosa and $R$. pseudoacacia seedlings}

The height in the defoliation treatments did not change significantly from the beginning to the end of the experiment compared with the CK treatment in both species, which was consistent with previous studies that plant height is insensitive to defoliation treatment (Pinkard and Beadle 1998). In addition, the results of our study did not support our first hypothesis that defoliation would reduce plant growth in total biomass at the end of the experiment. Instead, after 60 days of treatment, seedling total biomass did not decrease significantly in any defoliation treatment in both species, which indicates an equal compensatory mechanism (Trlica and Rittenhouse 1993). Therefore, we concluded that seedlings could return to normal levels in their early growth stage after being subjected to defoliation treatment. Our results are consistent with those reported previously in other species, which showed that moderate (50-66\%) defoliation did not affect growth in Nothofagus solandri var. cliffortioides seedlings (Mikola et al. 2000). Concerning plant growth, the biomass among organs was greatly affected by the defoliation treatment in the early stage. In our study, it was found that the biomass of leaves and stems in the TD treatment decreased significantly, and the biomass of roots in the TD treatment did not change significantly at day 3 of $R$. pseudoacacia (Table 1). This indicated that in the early stage after defoliation, seedlings reduced the allocation of stem biomass in order to cope with carbon source limitation and may increase carbohydrate investment to the construction of new leaves (Eyles et al. 2011), resulting in a trade-off between carbon source organ and carbon sink organ. This tradeoff type would allow seedlings to survive better under unfavorable conditions. We also found that the root biomass increased significantly in the BU treatment compared with the CK treatment of $R$. pseudoacacia at day 60 (Table 1), which stimulated the over-compensation mechanism of root for reserves accumulating. There were no significant differences in the total biomass of the seedlings, which may be related to the strategy of storing considerable carbon that made the growth not sensitive to stress (Palacio et al. 2013).

The allocation of non-structural carbohydrates in terms of growth, storage, and defense is mainly related to the rhythm of plant growth and development (Hartmann et al. 2013). After defoliation and until the photosynthetic capacity of new leaves recovers to the control level (days 1-14), the effect of defoliation on seedlings' NSC allocation in A. fruticosa and $R$. pseudoacacia was relatively large. During this period, the production of new leaves required a lot of carbohydrates (Quentin et al. 2011). The SS/ST ratio reflects NSC allocation, which could illustrate the conversion dynamics between soluble sugars and starch during the experimental period (Xie et al. 2018). In the early stage of defoliation (days 1-3), stem SS/ST decreased significantly in both species, mainly due to soluble sugar decrease, which may be related to increasing investment in growth to produce new leaves. New photosynthetic products will be preferentially assigned to organs (especially new leaves and stems) near the source, which requires large amounts of energy investment (Eyles et al. 2011). Thus, at the same time, we also found that the stem soluble sugar concentration decreased significantly in defoliation treatments at day 3 in both species (Fig. 6). However, the decrease in the root NSC concentration was mainly due to the decrease in soluble sugar concentration, and the starch concentration remained relatively stable. There was also a trend of a remobilization of the carbon reserve from these organs to satisfy the carbon demand to produce new leaves. In our study, we found 
that the stem starch concentration was reduced in the TD treatment of A. fruticosa at day 14, and R. pseudoacacia at day 3 (Fig. 6), which indicated that ST was converted into SS to compensate for the lack of carbohydrates after defoliation. Indeed, plants use their carbon reserves stored as starch in stems to meet soluble sugar demand for the construction of new leaves, and to compensate for the decrease of carbon synthesis because of leaves lost (Swank et al. 1981). The effect of defoliation on NSC allocation patterns had been fully recovered after 60 days, which was used to compensate for the defoliation damage (Quentin et al. 2011).

\subsection{Effects of defoliation modalities on $A$. fruticosa and $R$. pseudoacacia seedlings}

Seedlings are more sensitive to the removal of lower leaves (BU treatment) than upper leaves (TD treatment) in terms of leaf traits in both species. Our results showed that total chlorophyll concentration increased significantly in the BU treatment but not in TD in R. pseudoacacia (Fig. 5b), which indicated that defoliation led to improved nutrient content in newly developed leaves, potentially promoting photosynthetic rates (Ahmadi and Joudi 2007). Meanwhile, SLA was also significantly decreased in the BU treatment but not in the TD treatment in both species (Fig. 5 e and f), which indicated that plants could maximize the light energy utilization efficiency in their leaves by altering leaf morphology (Collins et al. 2012). Our study indicated that the leaf photosynthesis of R. pseudoacacia and A. fruticosa increased by $21 \%$ and $29 \%$, respectively, in the BU treatment compared with the CK at day 60 (Fig. 4 a and b). Similar results were also reported in a previous study on eucalypt species (Barry and Pinkard 2013). Moreover, another study reported that decreased SLA is related to increased leaf toughness (Knepp et al. 2005); tougher leaves are more difficult for insects to ingest (Bernays 1986).

Previous studies have reported that a range of tree species were able to compensate for partial defoliation (Ågren and Willson 1992; Johnson and Lincoln 2010), through a series of compensatory mechanisms (Anten and Ackerly 2010; Chen et al. 2001), such as increasing the photosynthetic rate of remaining leaves. In our study, the net photosynthetic rate of the remaining leaves in the TD treatment was significantly higher than $\mathrm{CK}$ at day 14 of $R$. pseudoacacia (Fig. 3c). This may be because defoliation of the upper leaves is likely to increase the penetration of light throughout the crown (Kosola et al. 2001; Quentin et al. 2011). Meanwhile, the net photosynthetic rate of the remaining leaves in the BU treatment was also significantly higher than $\mathrm{CK}$ at day 14 of R. pseudoacacia (Fig. 3d). This may be because defoliation decreased the source size, so the increased demand for carbohydrates from the remaining leaves, in turn, increased the photosynthetic rate of these leaves (Eyles et al. 2016; Sweet and Wareing 1966). In a study of Populus tremuloides, a tree species that is commonly defoliated by insects in North American forests, the compensatory photosynthetic effect was partly correlated with the rapid hydraulic responses of roots and leaves, owing to profound changes in the levels of leaf and root aquaporin expression, and this response was very fast (Liu et al. 2014). Moreover, we also found that the net photosynthetic rate of reflushing leaves in TD was significantly higher than that in BU at day 30 of A. fruticosa. After the upper leaves were removed, the remaining lower leaves gradually decreased in photosynthetic capacity as time passed. In order to maintain plant growth, the reflushing leaves in TD should increase the net photosynthetic rate. However, in the BU treatment, the remaining leaves were newly developed and could still perform photosynthesis normally, so the net photosynthetic rate of the reflushing leaves in BU did not increase.

Seedling carbon allocation was more susceptible to the BU treatment than the TD treatment in $R$. pseudoacacia. In the present study, it was found that the root NSC concentration under the BU treatment was significantly decreased compared with that under the TD treatment at day 14 in $R$. pseudoacacia (Fig. 6f), and a consistent trend was also found for SS/ST in R. pseudoacacia (Fig. 7f). Moreover, root NSC concentration in TD would recover to control levels at day 14 , but the root NSC concentration in BU would recover to control levels at day 30 in $R$. pseudoacacia. This may be related to different functional traits of the top and bottom crowns (Yoshimura 2013). The supply of assimilates from leaves follows the principle of near supply; therefore, the top leaves mainly distribute photosynthetic products to new leaves and stems, and the bottom leaves mainly distribute photosynthetic products to the roots (Palit 1985). After the bottom leaves were removed (BU treatment), the allocation of assimilates to the root was reduced.

\subsection{Different recovery strategies of $A$. fruticosa and $R$. pseudoacacia seedlings}

Increasing the photosynthetic capacity of the remaining leaves may be the most common and important tree compensation response after defoliation (Eyles et al. 2011). In our study, we found that the net photosynthetic rate of the remaining leaves in both TD and BU treatments of $R$. pseudoacacia increased significantly at day 14 (Fig. 3 c and d). However, we did not observe an increase in the net photosynthetic rate of A. fruticosa during the recovery period. $R$. pseudoacacia also increased its ability to capture light by increasing the chlorophyll concentration in the BU treatment at day 60 , but we did not observe an increase in chlorophyll concentration in A. fruticosa. Instead, increasing the carbon allocation to the above-ground parts and decreasing carbon allocation to the below-ground parts would be the recovery mechanism in 
A. fruticosa. Previous studies have demonstrated that after defoliation, plants tend to allocate more biomass to the above-ground parts (Oesterheld 1992; Wiley et al. 2017).

Growth and carbon allocation recovered rapidly after defoliation in both species, but $R$. pseudoacacia recovered relatively faster than A. fruticosa. Our study showed that NSC mass in $R$. pseudoacacia recovered to the control level at day 14, and NSC mass in A. fruticosa recovered to the control level at day 30 (Table 2). Thus, R. pseudoacacia could be more likely to quickly recover following defoliation by insects, making it more suitable for vegetation restoration. Previous studies also found that different species had different recovery mechanisms (Mukherjee et al. 2015), and $R$. pseudoacacia recovered through more compensatory physiological mechanisms in our study. Our results indicated that these compensatory mechanisms include (1) modification of leaf traits, such as increased chlorophyll concentration; (2) increasing photosynthetic rates in the remaining leaves; and (3) the remobilization of the carbon reserve stored in longterm compartments toward new-leaf production.

Although R. pseudoacacia is more susceptible to pests and diseases in nature than A. fruticosa, R. pseudoacacia is usually dominant in warm temperate forests and plays an important role in soil and water conservation (Zhang and Xing 2009). Previous studies have found that $R$. pseudoacacia seedlings could survive well under drought and shaded conditions (Xu et al. 2009). Although R. pseudoacacia is classified as an invasive species, a nitrogen-deposition experiment showed that this species did not threaten the growth of native Quercus acutissima seedlings, but a positive interaction between the two species was found (Ding et al. 2012). Our results indicated the rapid recovery of $R$. pseudoacacia following defoliation, which provides further important evidence of the suitability of this species for vegetation restoration.

\section{Conclusion}

Our study demonstrated that physiological indicators and carbon allocation were significantly affected by defoliation, especially during the early recovery period (days 1-14). Growth dynamics were related to the change in carbon allocation, and the seedling growth in both species could be recovered to control levels at the end of the experimental period. After the leaves were removed, A. fruticosa and R. pseudoacacia adopted a positive recovery strategy; however, the mechanisms used by $R$. pseudoacacia were more diverse than those used by A. fruticosa. According to the results, $R$. pseudoacacia recovered quickly following defoliation, and thus might be more suitable for vegetation restoration projects. The present study provides theoretical advice for the selection of species for vegetation restoration, and more species should be included in future studies to obtain more generalizable conclusions.
Acknowledgments Many thanks to Prof. Jian Liu from Shandong University for his thoughtful suggestions. We are very grateful to Shuna Liu from Shandong University for their help during the experiments.

Funding information The research was funded by the National Natural Science Foundation of China (No. 31400173), the Ministry of Science and Technology, China (No. 2015FY210200), the Natural Science Foundation of Shandong Province, China (No. ZR2014CQ038), and the Research Foundation of Qingdao Forest Ecosystem (No. 11200005071603).

Data availability The datasets generated during and/or analyzed during the current study are available from the corresponding author on reasonable request.

\section{Compliance with ethical standards}

Conflict of interest The authors declare that they have no conflict of interest.

Abbreviations $H$, seedling height; NSC, non-structural carbohydrate; $R_{L N}$, ratio of leaf NSC mass increment; $R_{R N}$, ratio of root NSC mass increment; $R_{S N}$, ratio of stem NSC mass increment; $S S / S T$, soluble sugar/starch ratio; $T B$, total biomass; $A_{R E M}$, net photosynthetic rate of remaining leaves; $A_{R E F}$, net photosynthetic rate of reflushing leaves

\section{References}

Ågren J, Willson MF (1992) Determinants of seed production in Geranium maculatum. Oecologia 92:177-182. https://doi.org/10. 1007/BF00317361

Ahmadi A, Joudi M (2007) Effects of timing and defoliation intensity on growth, yield and gas exchange rate of wheat grown under wellwatered and drought conditions. Pak J Agric Sci 10:3794-3800. https://doi.org/10.3923/pjbs.2007.3794.3800

Anten N, Ackerly D (2010) Canopy-level photosynthetic compensation after defoliation in a tropical understorey palm. Funct Ecol 15:252 262. https://doi.org/10.1046/j.1365-2435.2001.00517.x

Asao S, Ryan MG (2015) Carbohydrate regulation of photosynthesis and respiration from branch girdling in four species of wet tropical rain forest trees. Tree Physiol 35:608-620. https://doi.org/10.1093/ treephys/tpv025

Bansal S, Germino MJ (2009) Temporal variation of nonstructural carbohydrates in montane conifers: similarities and differences among developmental stages, species and environmental conditions. Tree Physiol 29:559-568. https://doi.org/10.1093/treephys/tpn045

Barry KM, Pinkard EA (2013) Growth and photosynthetic responses following defoliation and bud removal in eucalypts. For Ecol Manag 293:9-16. https://doi.org/10.1016/j.foreco.2012.12.012

Barry KM, Quentin A, Eyles A, Pinkard EA (2012) Consequences of resource limitation for recovery from repeated defoliation in Eucalyptus globulus Labilladière. Tree Physiol 32:24-35. https:// doi.org/10.1093/treephys/tpr128

Bernays EA (1986) Diet-induced head allometry among foliage-chewing insects and its importance for graminivores. Science 231:495-497. https://doi.org/10.1126/science.231.4737.495

Cao X, Zhu C, Zhong C, Hussain S, Zhu L, Wu L, Jin Q (2017) Mixednitrogen nutrition-mediated enhancement of drought tolerance of rice seedlings associated with photosynthesis, hormone balance and carbohydrate partitioning. Plant Growth Regul 84:451-465. https://doi.org/10.1007/s10725-017-0352-6 
Chen Z, Kolb TE, Clancy KM (2001) Mechanisms of Douglas-fir resistance to western spruce budworm defoliation: bud burst phenology, photosynthetic compensation and growth rate. Tree Physiol 21: 1159-1169. https://doi.org/10.1093/treephys/21.16.1159

Chuste P, Maillard P, Bréda N, Levillain J, Thirion E, Wortemann R, Massonnet C (2019) Sacrificing growth and maintaining a dynamic carbohydrate storage are key processes for promoting beech survival under prolonged drought conditions. Trees 34:381-394. https://doi. org/10.1007/s00468-019-01923-5

Cierjacks A, Kowarik I, Joshi J, Hempel S, Ristow M, von der Lippe M, Weber E (2013) Biological flora of the british isles: Robinia pseudoacacia. J Ecol 101:1623-1640. https://doi.org/10.1111/ 1365-2745.12162

Collins AM, Liberton M, Jones HD, Garcia OF, Pakrasi HB, Timlin JA (2012) Photosynthetic pigment localization and thylakoid membrane morphology are altered in Synechocystis 6803 phycobilisome mutants. Plant Physiol 158:1600-1609. https://doi.org/10.1104/pp. 111.192849

Dale AG, Frank SD (2017) Warming and drought combine to increase pest insect fitness on urban trees. PLoS One 12:e0173844. https:// doi.org/10.1371/journal.pone. 0173844

Dehaan LR, Ehlke NJ, Sheaffer CC, Wyse DL, Dehaan RL (2006) Evaluation of diversity among North American accessions of false indigo (Amorph a fruticosa L.) for forage and biomass. Genet Resour Crop Evol 53:1463-1476. https://doi.org/10.1007/s10722-0056845-6

Dewar RC (1993) A root-shoot partitioning model based on carbonnitrogen-water interactions and munch phloem flow. Funct Ecol 7: 356-368. https://doi.org/10.2307/2390216

Ding W, Wang R, Yuan Y, Liang X, Liu J (2012) Effects of nitrogen deposition on growth and relationship of and seedlings. Dendrobiology 67:3-13. https://doi.org/10.1080/01916122.2012. 684542

Eyles A, Smith D, Pinkard EA, Smith I, Corkrey R, Elms S, Beadle C, Mohammed C (2011) Photosynthetic responses of field-grown Pinus radiata trees to artificial and aphid-induced defoliation. Tree Physiol 31:592-603. https://doi.org/10.1093/treephys/tpr046

Eyles A, Barry KM, Quentin AG, Pinkard EA (2013a) Impact of defoliation in temperate eucalypt plantations: physiological perspectives and management implications. Forest Ecol Manag 304:49-64. https://doi.org/10.1016/j.foreco.2013.04.033

Eyles A, Pinkard EA, Davies NW, Corkrey R, Churchill K, O'Grady AP, Sands P, Mohammed C (2013b) Whole-plant versus leaf-level regulation of photosynthetic responses after partial defoliation in Eucalyptus globulus saplings. J Exp Bot 64:1625-1636. https:// doi.org/10.1093/jxb/ert017

Eyles A, Pinkard EA, O'Grady AP, Corkrey R, Beadle C, Mohammed C (2016) Recovery after defoliation in Eucalyptus globulus saplings: respiration and growth. Trees 30:1-13. https://doi.org/10.1007/ s00468-016-1388-3

Galiano L, Martinez-vivalta J, Lloret F (2011) Carbon reserves and canopy defoliation determine the recovery of scots pine $4 \mathrm{yr}$ after a drought episode. New Phytol 190:750-759. https://doi.org/10. 1111/j.1469-8137.2010.03628.x

Guo X, Ren X, Eller F, Li M, Wang R, Du N, Guo W (2018) Higher phenotypic plasticity does not confer higher salt resistance to Robinia pseudoacacia than Amorpha fruticosa. Acta Physiol Plant 4:40-79. https://doi.org/10.1007/s11738-018-2654-3

Hartmann H, Ziegler W, Trumbore S (2013) Lethal drought leads to reduction in nonstructural carbohydrates in Norway spruce tree roots but not in the canopy. Funct Ecol 27:413-427. https://doi.org/10. 1111/1365-2435.12046

Hinman ED, Fridley JD (2018) To spend or to save? Assessing energetic growth-storage tradeoff in native and invasive woody plants. Oecologia 188:659-669. https://doi.org/10.1007/s00442-018$4177-4$
Jacquet J, Bosc A, O'Grady A, Jactel H (2014) Combined effects of defoliation and water stress on pine growth and non-structural carbohydrates. Tree Physiol 34:367-376. https://doi.org/10.1093/ treephys/tpu018

Johnson SL, Lincoln DE (2010) Allocation responses to $\mathrm{CO}_{2}$ enrichment and defoliation by a native annual plant Heterotheca subaxillaris. Glob Chang Biol 6:767-778. https://doi.org/10.1046/j.1365-2486. 2000.00355.x

Karolewski P, Zadworny M, Mucha J, Napierałafilipiak A, Oleksyn J (2010) Link between defoliation and light treatments on root vitality of five understory shrubs with different resistance to insect herbivory. Tree Physiol 30:969-978. https://doi.org/10.1093/treephys/ tpq060

Knepp RG, Hamilton JG, Mohan JE, Zangerl AR, Berenbaum MR, DeLucia EH (2005) Elevated $\mathrm{CO}_{2}$ reduces leaf damage by insect herbivores in a forest community. New Phytol 167:207-218. https:// doi.org/10.1111/j.1469-8137.2005.01399.x

Korpita T, Orians CM (2014) Cues from a specialist herbivore increase tolerance to defoliation in tomato. Funct Ecol 28:395-401. https:// doi.org/10.1111/1365-2435.12184

Kosola KR, Dickmann DI, Paul EA, Parry D (2001) Repeated insect defoliation effects on growth, nitrogen acquisition, carbohydrates, and root demography of poplars. Oecologia 129:65-74. https://doi. org/10.1007/s004420100694

Krause SC, Raffa KF (1996) Differential growth and recovery rates following defoliation in related deciduous and evergreen trees. Trees 10:308-316. https://doi.org/10.1007/BF02340777

Kuosmanen N, Marquer L, Tallavaara M, Molinari C, Zhang Y, Alenius $\mathrm{T}$, Edinborough K, Pesonen P, Reitalu T, Renssen H, Trondman AK, Seppa H (2018) The role of climate, forest fires and human population size in Holocene vegetation dynamics in Fennoscandia. $\mathrm{J}$ Veg Sci 29:382-392. https://doi.org/10.1111/jvs.12601

Leather SR, Watt AD, Forrest GI (2010) Insect-induced chemical changes in young lodgepole pine (Pinus contorta): the effect of previous defoliation on oviposition, growth and survival of the pine beauty moth, Panolis flammea. Ecol Entomol 12:275-281. https://doi.org/ 10.1111/j.1365-2311.1987.tb01006.x

Lichtenthaler H, Wellburn AR (1983) Determination of total carotenoids and chlorophylls a and b of leaf in different solvents. Biochem Soc Trans 11:591-592. https://doi.org/10.1042/bst0110591

Liu J, Equiza M, Navarro-Rodenas A, Lee S, Zwiazek J (2014) Hydraulic adjustments in aspen (Populus tremuloides) seedlings following defoliation involve root and leaf aquaporins. Planta 240:553-564 https://www.jstor.org/stable/43565811

Liu J, Arend M, Yang W, Schaub M, Ni Y, Gessler A, Jiang Z, Rigling A, Li M (2017) Effects of drought on leaf carbon source and growth of European beech are modulated by soil type. Sci Rep 7:42462. https://doi.org/10.1038/srep42462

Lourens P, Imole MD, Alfredo A, Esther F, Juan-Carlos L, Marielos PC, Frank S, Zulma V, Ute SK (2010) The importance of wood traits and hydraulic conductance for the performance and life history strategies of 42 rainforest tree species. New Phytol 185:481-492. https://doi. org/10.1111/j.1469-8137.2009.03092.x

Mikola J, Barker GM, Wardle DA (2000) Linking above-ground and below-ground effects in autotrophic microcosms: effects of shading and defoliation on plant and soil properties. Oikos 89:577-587. https://doi.org/10.1034/j.1600-0706.2000.890318.x

Mukherjee JR, Jones TA, Adler PB, Monaco TA (2015) Contrasting mechanisms of recovery from defoliation in two intermountainnative bunchgrasses. Rangel Ecol Manag 68:485-493. https://doi. org/10.1016/j.rama.2015.07.011

Nautiyal PC, Ravindra V, Joshi YC (1999) Net photosynthetic rate in peanut (Arachis hypogaea L.): influence of leaf position, time of day, and reproductive-sink. Photosynthetica 36:129-138. https:// doi.org/10.1023/A:1007079022742 
Oesterheld M (1992) Effect of defoliation intensity on aboveground and belowground relative growth rates. Oecologia 92:313-316. https:// doi.org/10.1007/BF0031745

Palacio S, Hoch G, Sala A, Körner C, Millard P (2013) Does carbon storage limit tree growth? New Phytol 201:1096-1100. https://doi. org/10.1111/nph.12602

Palit P (1985) Translocation and distribution of ${ }^{14} \mathrm{C}$-labelled assimilate associated with growth of jute (Corchorus olitorius L.). Funct Plant Biol 12:527-534. https://doi.org/10.1071/PP9850527

Petrović J, Ćurčić S, Stavretović N (2016) Invasive plant species and ecological factors influencing the spreading in the area of the Obrenovački Zabran Nature Monument (Central Serbia). Šumarski list

Pinkard EA, Beadle CL (1998) Regulation of photosynthesis in Eucalyptus nitens (Deane and Maiden) Maiden following green pruning. Trees 12:366-376. https://doi.org/10.1007/PL00009722

Piper FI, Fajardo A, Hoch G (2017) Single-provenance mature conifers show higher non-structural carbohydrate storage and reduced growth in a drier location. Tree Physiol 37:1-10. https://doi.org/ 10.1093/treephys/tpx061

Qiu C, Ethier G, Pepin S, Xu Q, Gosselin A, Desjardins Y (2016) Hydraulic and photosynthetic compensation versus fruit yield of red raspberry following partial leaf defoliation. Sci Hortic 213:6675. https://doi.org/10.1016/j.scienta.2016.10.007

Quentin AG, Pinkard EA, Beadle CL, Wardlaw TJ, O'Grady AP, Paterson S, Mohammed CL (2010) Do artificial and natural defoliation have similar effects on physiology of Eucalyptus globulus Labill. seedlings? Ann Forest Sci 67:203-203. https://doi.org/10. 1051/forest/2009096

Quentin AG, Beadle CL, O'Grady AP, Pinkard EA (2011) Effects of partial defoliation on closed canopy Eucalyptus globulus Labilladière: growth, biomass allocation and carbohydrates. For Ecol Manag 261:695-702. https://doi.org/10.1016/j.foreco.2010. 11.028

Richardson AD, Carbone MS, Keenan TF, Czimczik CI, Hollinger DY, Murakami P, Schaberg PG, Xu X (2013) Seasonal dynamics and age of stemwood nonstructural carbohydrates in temperate forest trees. New Phytol 197:850-861. https://doi.org/10.1111/nph.12042

Rieske LK, Dillaway DN (2008) Response of two oak species to extensive defoliation: tree growth and vigor, phytochemistry, and herbivore suitability. For Ecol Manag 256:121-128. https://doi.org/10. 1016/j.foreco.2008.04.015

Root TL, Price JT, Hall KR, Schneider SH, Cynthia RJ, Alan P (2003) Fingerprints of global warming on wild animals and plants. Nature 421:57-60. https://doi.org/10.1038/nature01333

Schmid S, Palacio S, Hoch G (2017) Growth reduction after defoliation is independent of $\mathrm{CO}_{2}$ supply in deciduous and evergreen young oaks. New Phytol 214:1479-1490. https://doi.org/10.1111/nph.14484

Sharma A, Sood A, Verma TD (2008) Insect-pests associated with, Robinia pseudoacacia, in the agroforestry system in mid-hill regions of Himachal Pradesh. Indian Forester 134:120-124 https://doi.org/ $10.36808 /$ if $\% 2 \mathrm{~F} 2008 \% 2 \mathrm{Fv} 134 \mathrm{i} 1 \% 2 \mathrm{~F} 662$
Swank WT, Waide JB, Crossley DE, Todd RL (1981) Insect defoliation enhances nitrate export from forest ecosystems. Oecologia 51:297299. https://doi.org/10.1007/BF00540897

Sweet GB, Wareing PF (1966) Role of plant growth in regulating photosynthesis. Nature 210:77-79. https://doi.org/10.1038/210077a0

Trlica MJ, Rittenhouse LR (1993) Grazing and plant performance. Ecol Appl 3:21-23. https://doi.org/10.2307/1941783

Wang R, Zhou G (2000) The vegetation of Shandong Province. Shandong Science and Technology Publisher, Jinan

Weber E, Sun SG, Li B (2008) Invasive alien plants in China: diversity and ecological insights. Biol Invasions 10:1411-1429. https://doi. org/10.1007/s10530-008-9216-3

Wiley E, Huepenbecker S, Casper BB, Helliker BR (2013) The effects of defoliation on carbon allocation: can carbon limitation reduce growth in favour of storage? Tree Physiol 33:1216-1228. https:// doi.org/10.1093/treephys/tpt093

Wiley E, Casper BB, Helliker BR, Bonser S (2017) Recovery following defoliation involves shifts in allocation that favour storage and reproduction over radial growth in black oak. J Ecol 105:412-424. https://doi.org/10.1111/1365-2745.12672

Wilson D, Cooper JP (1969) Apparent photosynthesis and leaf characters in relation to leaf position and age, among contrasting Lolium genotypes. New Phytol 68:645-655. https://doi.org/10.1111/j.14698137.1969.tb06468.x

Wyka S, Mcintire C, Smith C, Munck I, RockB AH, Broders KD (2017) Effect of climatic variables on abundance and dispersal of Lecanosticta acicola spores and impact of defoliation on eastern white pine. Phytopathology 108:374-383. https://doi.org/10.1094/ PHYTO-02-17-0065-R

Xie H, Yu M, Cheng X (2018) Leaf non-structural carbohydrate allocation and $\mathrm{C}: \mathrm{N}: \mathrm{P}$ stoichiometry in response to light acclimation in seedlings of two subtropical shade-tolerant tree species. Plant Physiol Biochem 124:146-154. https://doi.org/10.1016/j.plaphy. 2018.01.013

Xu F, Guo W, Wang R, Xu W, Du N, Wang Y (2009) Leaf movement and photosynthetic plasticity of black locust (Robinia pseudoacacia) alleviate stress under different light and water conditions. Acta Physiol Plant 31:553-563. https://doi.org/10.1007/s11738-0080265-0

Yang Y, Watanabe M, Li F, Zhang J, Zhang W, Zhai J (2005) Factors affecting forest growth and possible effects of climate change in the Taihang Mountains, northern China. Forestry 79:135-147. https:// doi.org/10.1093/forestry/cpi062

Yoshimura K (2013) Influences of phenological differences on leaf-level carbon budget between the upper and lower crown of Lyonia ovalifolia. Botany 91:25-33. https://doi.org/10.1139/cjb-2012-0129

Zhang J, Xing S (2009) Research on soil degradation of Robinia pseudoacacia plantation under environmental stress (in Chinese with English abstract). Chin J Soil Sci 40:1086-1090

Publisher's note Springer Nature remains neutral with regard to jurisdictional claims in published maps and institutional affiliations. 